



\title{
Reflexiones teóricas sobre la corrupción: sus dimensiones política, económica y social
}

\author{
Estévez, Alejandro M.*
}

\section{Resumen}

El presente artículo tiene como objetivo dar cuenta del "estado del arte" en los temas de corrupción. Se analizó la bibliografía disponible utilizando tres perspectivas científicas, la política, la económica y la social. Asimismo, se intentó tener una visión de conjunto del fenómeno de la corrupción, es por ello que se consideran fuertemente las visiones culturales, sistémicas y organizacionales. Se concluye que existen al menos cinco factores estructurales que dan forma a la corrupción: a) Concentración de poder y riquezas asociadas a la impunidad, b) Profundización de las desigualdades sociales tanto en lo material como en los derechos y en los deberes, c) Racionalidad instrumental-eficientismo-pragmatismo, d) Caída de ciertos valores como fundamento de las decisiones públicas-tecnocracia, y e) Egoísmo-individualismo-razón individual.

Palabras clave: Corrupción, gobernabilidad, fraude, desorden, transparencia.

\section{Theoretical reflections on corruption: its political, economic and social dimensions}

\section{Abstract}

The objective of this article is to appreciate the state of the art in relation to the topic of corruption. Available bibliography is analyzed from three scientific perspectives: the political, the economic and the social, There is also an attempt to develop a vision of the phenomenon of corruption as a whole, and it is for this reason that cultural, systemic and organizational perspectives are stongly considered. The conclusion is that there are at leat five structural factors that form the concept of corruption: a) concentration of power associated with impunity, b) the deepening of social inequalities both materially as well as in relation to rights and obligations, c) instrumental rationality-efficiency and pragmatism, d) the loss of certain fundamental values in public technical decision-making, and e) egotism, individualism, individual reasoning.

Key words: Corruption, governability, fraud, disorder, transparency.

Recibido: 04-02-16. Aceptado: 05-01-21

Investigador del Centro de Investigaciones en Administración Pública de la Facultad de Ciencias Económicas, Universidad de Buenos Aires (Argentina). E-mail: aestevez@polipub.org 


\section{Introducción}

Desde su explosión en la década del '90, la corrupción ha irrumpido como un factor disruptivo en la realidad internacional. Habermas (1998) habla de un marco internacional de tensión, resultante de la interacción de tres líneas de fenómenos que han atravesado el pasado siglo haciéndose especialmente complejas hacia su fin. Estas serían, la explosión demográfica, la aparición de un cuarto sector laboral (conocimiento y técnica de comunicaciones) y la actitud instrumental de la ciencia ante la naturaleza. A estas tres líneas, permítasenos sumar el proceso paulatino y creciente de democratización.

Al día de hoy, no existe país, región, bloque o continente que no padezca los efectos de esta realidad multifacética. Las distintas áreas de los Estados se han visto sorprendidas por prácticas corruptas que difícilmente parecen ceder ante los esfuerzos combinados de los actores sociales. Si bien la corrupción es un fenómeno complejo que admite múltiples explicaciones, nos centraremos en la clásica tríada de política, economía y sociedad.

En el ámbito político, la corrupción ha favorecido el crecimiento de la inestabilidad institucional y el persistente desgaste de las relaciones tanto entre individuos como entre instituciones y Estados. La pérdida de legitimidad política que experimentan muchos gobiernos, la polarización del poder, la ineficiencia burocrática, etc., son algunos de los problemas políticos que se atribuyen a la acción de la corrupción. El creciente desarrollo de bloques políticos da nuevos aires a esta cuestión, poniendo en la agenda interna- cional como una prioridad relevante la necesidad de una acción colectiva anticorrupción.

Las nuevas tecnologías de comunicación e informática, han acrecentado el impacto de ciertas prácticas corruptas. Desde el punto de vista económico, la creación de una red electrónica internacional a través de la cual opera el nuevo sistema financiero ha presentado un sinnúmero de interrogantes acerca de cómo regular, controlar y evitar posibles fraudes informáticos. La experiencia nos muestra que la corrupción se vale de los "paraísos fiscales", la existencia de monopolios, la evasión impositiva, la licitación de grandes obras civiles, la privatización de empresas estatales, etc. para nutrirse de los recursos nacionales e internacionales tanto públicos como privados.

Desde la óptica social, la corrupción se ha instalado como factor determinante de los escenarios de extrema pobreza que padecen grandes proporciones del planeta. Asimismo, los conflictos entre las diversas jerarquías sociales y su involucramiento en luchas por poder y beneficios personales, han demostrado la necesidad de repensar la estructura, relación y distancia de los distintos estratos sociales. La cuestión étnica también ha sido permeable a la corrupción, avivando en muchos países los conflictos raciales. En orden a una mejor conceptualización de esta faceta de la corrupción, la literatura le otorga un papel preponderante a la transparentación de la información y al fortalecimiento de la confianza interpersonal como medios para refortalecer el vínculo social entre los distintos actores.

Dada la importancia que ha cobrado el tema, el objetivo de este trabajo es 
examinar las líneas generales de la investigación internacional sobre la corrupción. Pretendemos señalar los elementos esenciales de las distintas ópticas que han abordado la problemática de este fenómeno.

\section{Definición del concepto corrupción}

Al analizar la bibliografía disponible sobre corrupción, nos encontramos que el fenómeno ha sido estudiado desde diversas perspectivas en las ciencias sociales, por lo tanto, hemos procedido a analizarla desde las tres más representativas; la política, la económica y la social. En la perspectiva política se pone el acento en el análisis del poder y de los sistemas políticos; en la económica se observa una concentración en torno a la idea de cómo la corrupción afecta la eficiencia y en la social, analizamos los factores culturales, religiosos y morales.

El sustantivo corrupción proviene del latín corruptio, éste significaba para los clásicos romanos algún tipo de alteración. Esta alteración es interpretada como algo negativo. Es significativo que el uso más antiguo que encontramos de la palabra es el de la muerte de los seres vivos. La corrupción es el opuesto de la generación de la vida ${ }^{1}$.
Corruptio proviene a su vez del verbo corrumpere que significa echar a perder, descomponer // destruir // pervertir. La raíz verbal rumpere tiene origen onomatopéyico, es decir, intenta imitar el sonido de algo para significarlo. Rumpere quiere imitar el sonido de algo que se rompe de un modo cualquiera. El romano atiende en esta palabra el hecho mismo de algo que se rompe y no en el modo por el que éste algo pudo haberse roto (quebradura, caída, explosión, implosión, etc.). Corrumpere añade al carácter de alteración que separa que había significado corruptio el hecho de romperse. La corrupción es entonces una alteración que separa rompiendo. La corrupción es un proceso de desnaturalización. A medida que ella evoluciona, la cosa va dejando de ser lo que era.

Sentadas las bases de la etimología de "corrupción", nos proponemos ahora elaborar el concepto de corrupción operativo para la investigación. Para ello nos hemos valido del estudio de las formulaciones tradicionales y modernas del mismo: La definición tradicional de "corrupción" es "introducción de vicio o abuso en la relación entre hombres o cosas". Esta definición tiene un importante aporte al esclarecimiento de nuestro concepto: la corrupción es un mal que por exceso o defecto desnaturaliza una relación. Sin

1 Es interesante detenerse en el sustantivo paralelo a corruptio que la lengua latina nos ofrece: seductio, seducción en castellano. ¿Pero qué relación existe entre corrupción y seducción? A primera vista, resulta curiosa sino difícil de imaginar la relación ente estos dos conceptos. Veamos el criterio romano para trazar el paralelo. Seductio y su verbo de origen seducere son palabras compuestas por el prefijo se y la raíz verbal duc que significa conducción, mando, dirección. Se-ductio es dirigir separando, llevar aparte, separar. La similitud que encuentra el romano entre éstos dos conceptos es de un fuerte sentido material, ambos significan una cierta separación. Corruptio es una alteración que separa. 
embargo, la definición completa no satisface las exigencias de nuestro trabajo ya que amplía en exceso la extensión del concepto al generalizar su comprensión "hombres o cosas". Todo ente material sería plausible de este tipo de corrupción. Pero nosotros pretendemos circunscribirnos al ámbito humano. Precisamos entonces una comprensión específica de las cosas humanas que nos permita reducir la extensión del concepto al hombre.

La acepción moderna de "corrupción" es "confusión entre lo público y lo privado" utilizada en beneficio de un privado. Ésta nueva definición nos brinda otra nota clave en la búsqueda de nuestro fenómeno. La corrupción implica al hombre desde dos ópticas distintas, una que podríamos llamar ex intra (desde dentro) y otra ex extra (desde fuera). Sin embargo, la definición moderna acarrea ciertos problemas de extensión. ¿Habría corrupción en una sociedad patriarcal donde todo bien es propiedad privada del jefe de clan? ¿Y en una empresa privada donde un empleado se valiera de su posición para obtener un rédito personal? ¿Dónde están los límites claros entre el rol público y el privado; Estado y sociedad; gobierno y Estado; política y administración; intereses, derechos y obligaciones individuales y colectivas?

Cabe reconocer, que toda definición, en sí misma presenta un problema, porque según restrinjamos o agrandemos el sentido o alcance semántico del término, lo hacemos proporcionalmente con el fenómeno bajo estudio. A continuación, exponemos diversas definiciones de corrupción, a los efectos de mostrar las diferentes perspectivas desde las que puede abordarse el tema.
Para Galli (1996: 214): "La corrupción es un fenómeno que altera o trastoca la forma de alguna cosa. Pero puede referirse a realidades materiales 0 morales, por lo que aparecen varios sentidos del término que nos ayudan a precisar nuestro objeto. Hay formas de corrupción de las cosas materiales y otra formas de corrupción de las acciones morales." En esta definición observamos una reflexión sobre los planos éticos y materiales del fenómeno. En nuestro caso no nos centraremos sobre las cuestiones materiales, porque creemos que la corrupción está fincada en el plano del obrar de los actores.

Malem Seña (2000: 28), al intentar una definición del fenómeno, pone especial atención en la "posición del agente", por lo tanto habrá corrupción en: "aquellos actos que constituyen la violación activa o pasiva, de un deber posicional o del incumplimiento de alguna función específica realizados en el marco de discreción con el objeto de obtener algún beneficio extraposicional, cualquiera sea su naturaleza". En este caso observamos una preocupación por el agente y la trasgresión respecto de un cierto marco normativo.

Mauro (1997: 1), por otra parte, entiende a la corrupción como: "aquellas prácticas ilegales que afectan la eficiencia del gobierno". Aquí observamos una clásica definición que proviene de la ciencia económica, en la cual se focaliza sobre el ámbito público y la idea de eficiencia. Pero se excluye el accionar de agentes del sector privado sobre funcionarios para obtener beneficios sectoriales o personales.

Para Seligson (2002: 1) corrupción es: "el abuso de los funcionarios públicos para obtener ganancias privadas". Esta definición parecería exculpar a los agen- 
tes privados que serían parte de la relación de corrupción.

En el caso de Andvig y Odd-Helge (2000) será un: "comportamiento de un representante del Estado y de la autoridad pública orientada hacia la consecución de ganancias privadas". En esta misma línea, para Pritzl (2000) la corrupción es un: "abuso de la función publica en pos de un beneficio privado".

Para Heindenheimer (1990: 6) "la corrupción es una transacción entre actores del sector público y privado por medio de la cual ciertos bienes colectivos son ilegítimamente convertidos en retribuciones privadas".

Pero estas definiciones, observamos que dejan fuera de su alcance a una cierta cantidad de aspectos que no son desdeñables, a saber, las relaciones que se establecen entre los Estados (público-público) incluyendo las dimensiones relativas de ambas partes; o en una economía globalizada, la relación entre dos privados con distintos recursos y capacidades; o la cuestión de la direccionalidad, no siempre toda acción de corrupción comienza en el sector público, dado que hay actores activos y pasivos.

Por otro lado, creemos que exagerar la división entre público y privado respecto de los comportamientos de ciertos actores puede resultar una práctica engañosa, dado que la actividad pública es muy difícil de aislar de la actividad privada. El mercado y el Estado tienen múltiples interconexiones, si bien por necesidades teóricas se los separa, hay que reconocer que en la realidad funcionan superpuestos. Entonces, no es una decisión apropiada separar la moralidad del sector privado respecto de la que se pue- de observar en el sector público, las dos explican el conjunto. Mauro (1995) habla de corrupción pública y privada; a la privada la liga al crimen organizado o a los actos ilegales de los individuos, y la pública la relaciona a aquellas prácticas ilegales que afectan la eficiencia del gobierno.

La realidad latinoamericana, lamentablemente, es pródiga en ejemplos de corrupción de diversa índole. Hemos asistido a numerosas quiebras fraudulentas de empresas o el vaciamiento de las mismas por sus directivos -con el consecuente daño que le provocan a la economía-; o donde ciertos partidos políticos o sindicatos han sido utilizados como "propiedad privada" por sus dirigentes llevándolos al colapso sin importarles el desgaste que le provocaban al sistema democrático.

A los efectos de adoptar una definición que sea útil para nuestro estudio, diremos que la corrupción será toda acción u omisión de un actor, que confunda lo público con lo privado, a los efectos de obtener algún beneficio personal. Pero creemos que no hay que ceñir lo público a lo estrictamente estatal, es decir, que allí en donde un gerente de una empresa, realice maniobras a los efectos de apropiarse de rentas de forma indebida, o donde un sindicalista se aproveche de su organización en términos propios, habrá también corrupción. Como dijéramos anteriormente, este trabajo tratará sobre la corrupción desde una perspectiva política, económica y social; veremos ahora las razones y efectos políticos.

\section{Razones y efectos políticos}

Para la teoría política clásica, la reflexión sobre la corrupción no es un tópico 
nuevo. Desde la antigua Grecia, pasando por el renacimiento y la modernidad, el desvío de las formas de gobierno "puras" de su objetivo del bien común, era considerado como un claro indicio de corrupción. Ya en la modernidad, y con la distinción entre lo público y lo privado, el pensamiento político en torno a la corrupción se centró en aquellas acciones individuales que utilizaban en provecho propio los bienes públicos. Pero así y todo, la reflexión política sobre la corrupción cubre un amplio espectro de temas que pueden ir desde los sistemas políticos y la estructura institucional, el poder, la centralización y la descentralización, la consolidación democrática, hasta el tamaño del Estado y la legitimidad de los gobiernos.

En términos generales, el mayor efecto de la corrupción política (el concepto corrupción política crea ruido, este punto se refiere a razones y efectos políticos de la corrupción, lo cual es distintos a corrupción política, concepto que no se define en el trabajo, recomiendo referirse solo a la corrupción y no a la corrupción política) es la impotencia e incapacidad del Estado. La corrupción va corroyendo poco a poco la capacidad del Estado de recaudar impuestos; de implementar políticas de desarrollo coherentes y racionales; de redistribuir los recursos entre los diferentes grupos y regiones; de transformar para bien la sociedad siguiendo prioridades sociales y políticas. En pocas palabras, la corrupción política, en la mayoría de los casos, impide que una comunidad política alcance sus objetivos, porque ataca el mecanismo decisiones sociales (revisar, hay problemas de redacción, no se entiende) (Andvig y Odd-Helge, 2000).
La aparición de la corrupción dispara una serie de procesos que de no enfrentarse a tiempo tienden a desarrollar círculos viciosos corruptos que se autoalimentan. Por ejemplo: las regulaciones burocráticas que están estructuradas en forma confusa permiten a los funcionarios recibir sobornos y obtener ventajas personales gracias a su labor de interpretar, detener o acelerar estos procesos, despreocupándose de la cuestión pública y de su verdadero trabajo. En estas condiciones, surge un enrarecido clima de inseguridad que va desgastando los lazos de confianza interpersonales y los existentes entre la ciudadanía y las instituciones y poderes del Estado. Estas condiciones socavan la legitimidad del gobierno de turno, a la par que desacreditan toda la cuestión política en sí. La corrupción es entonces percibida como una falta a la justicia social que amenaza, más allá de los distintos sistemas políticos y posibles estructuras de las instituciones, con capturar al Estado y reducirlo a un conjunto inorgánico de luchas de poder (Malem Seña, 2000).

\subsection{La concentración de poder}

La concentración del poder como fuente de la corrupción ha sido un tema clásico de la ciencia política. Esta tendencia se ve claramente en el pensamiento contractualista en el cual se pensaba que la mejor forma de evitar el abuso del poder era fraccionándolo y buscando el control recíproco de las partes.

En el pensamiento pluralista, como tributario de la corriente precedente, se observa también esta idea de que un cierto fraccionamiento social es positivo para 
el sistema si las partes compiten entre si. El supuesto sería que hay un molde democrático por fuera del cual es imposible competir.

Según Tiihonen (2003), una de las razones de la baja corrupción que se constata en Finlandia es justamente la estructura colectiva y colegiada de decisión que tiene el país. En el pensamiento de este autor se elogia a las formas colegiadas como difíciles de corromper si la mayoría de sus miembros están convencidos de ciertos valores éticos. Por ello, la decisión colegiada ha sido en Finlandia una tradición desde el siglo XVII. Por otro lado, existe un sistema de doble control en los organismos públicos; para que la decisión de un ministro sea válida, debe estar acompañada por la firma de un funcionario de un jerarquía menor conocido como "rapporteur". Sin esta doble signatura, el acto público no está completo.

\subsection{El desequilibrio de poder de tipo unitario o federal}

Según Andvig y Odd-Helge (2000), el desequilibrio de poder de tipo unitario o federal es otra posible causa política de corrupción. Algunos investigadores sostienen que "los sistemas políticos descentralizados son más corruptibles dado que los agentes corruptores necesitan influir en sólo un segmento del gobierno (...). En un sistema fragmentado existen menos fuerzas y agencias centralizadas para asegurar la honestidad" (Banfield, 1979). Algunos inclusive destacan que probablemente existan más oportunidades para la corrupción a nivel local en un esquema de gobierno federal ya que los funcionarios locales poseen más poder de decisión que los responsables del ámbito nacional (Proud'homme, 1995). Otros Investigadores consideran que los políticos locales son más susceptibles a las presiones de los intereses de su zona, tal como señala Tanzi (2000), en materia impositiva.

Algunos trabajos dejan entrever que la condición para que la estructura federal no engendre un nuevo tipo de corrupción más difícil de controlar es la no fragmentación del sistema federal. Es decir, que el Estado en proceso de descentralización no desatienda la implementación de controles específicos a las nuevas subestructuras (Treisman, 2000).

Otros autores se han abocado a la investigación sobre los efectos de la descentralización política y administrativa en el fenómeno de la corrupción. Huther y Shah (2000) y Fishman y Gatti (2000) encontraron evidencia de la relación entre una mayor descentralización fiscal en el gasto público y un menor nivel de corrupción.

Lederman (2001), por otra parte, sugiere que la descentralización política que consiste en dar más autonomía a las regiones de modo que puedan legislar en ámbitos cuya jurisdicción era del gobierno central, aumenta la corrupción. Sin embargo, el mismo estudio indica que la descentralización que supone una mayor autonomía sobre el gasto público, tendería a reducir la corrupción.

En esta misma línea se encuentran algunos autores que afirman que un Estado de tipo federal contribuye a la creación de un gobierno más honesto y eficiente, a través de la competencia de la distintas provincias y jurisdicciones (Weingast, 1995). De los estudios consultados no 
pareciera surgir una base empírica suficiente como para poder afirmar una relación de implicancia estricta entre descentralización o centralización y corrupción. Sin embargo, la investigación en este ámbito está brindando actualmente una mayor cantidad de elementos para juzgar la totalidad del problema como atestigua la creciente publicación de trabajos al respecto.

\subsection{Deficiencias del sistema político}

La Ciencia Política tradicional ha considerado que las causas de la corrupción están radicadas en las deficiencias del sistema político, en particular en el "déficit democrático" (Andvig y Odd-Helge, 2000). A partir de la investigación de Doig y Theobald (2000) podemos caracterizar éste déficit como "los sistemas políticos deficientes que carecen de democracias óptimas con división de poderes; y de métodos de inspección y de balance de instituciones".

En general, la relación entre corrupción y democracia es considerada negativa, es decir, que cuanto menos democrático es un sistema político, más corrupto también. La corrupción política generalizada está considerada como efecto de un estado deficiente, con una severa falla de buena gobernancia, liderazgo ético y consistencia democrática (Hope, 2000). La Ley de Democratización (Friedrich, 1989) que establece que el grado de corrupción varía inversamente respecto al grado de consenso del poder, también apoya a lo que se ha convertido en el argumento básico y más práctico contra la corrupción y sus causas: La corrupción sólo puede ser revertida en un marco de democratización del Estado. Según Amundsen (1999), dentro del grupo de los sistemas no democráticos parece confirmarse la relación entre formas autoritarias de poder y escenarios con un alto nivel de corrupción.

Por el contrario, según Andvig y Odd-Helge (2000), es importante tener en cuenta que el control autoritario de la política y la economía implica también un estricto control sobre los niveles de corrupción y los mecanismos de distribución de los recursos. Little (1992) señala que los gobiernos militares en los países del Tercer Mundo han padecido una mayor corrupción a nivel de derechos humanos que a nivel económico. En esta línea, Naim (1995) indica que mientras que en los gobiernos autoritarios la corrupción está institucionalizada y por lo tanto es predecible y controlable, en los gobiernos democráticos está librada a la competencia y al hecho de que una mayor participación de actores implica una mayor cantidad de potenciales corruptos.

Finalmente, Andvig y Odd-Helge (2000) concluye que las teorías más esquemáticas encuentran una relación inversamente proporcional entre corrupción y democracia. Sin embargo, una teoría mejor elaborada sostendría que la relación no es lineal sino acampanada. Es decir, que mientras que en el período de transición de una dictadura hacia una democracia encontramos altos niveles de corrupción, en los estadios de estabilidad tanto la forma totalitaria como la democrática pueden subsistir sin una gran presencia de corrupción. Las formas estables de gobierno tienden a poder controlar el nivel de corrupción y a mantenerlo en grados viables. 


\subsection{Democracias incipientes}

Según Leys (1970), los Estados nacientes son más permeables a la corrupción debido a que en ellos la constitución de la identidad nacional es joven y por lo tanto no existe una idea orgánica de interés nacional. En estos nuevos Estados existen reglas que aún no han sido internalizadas, por lo cual su violación muchas veces no es considerada como algo grave.

Por su parte, Weyland (1998) señala que la corrupción registraría niveles más altos en las democracias emergentes de regímenes autoritarios, especialmente en Latinoamérica. Para justificar esta afirmación el autor se vale de tres causas fundamentales: a) La democracia tiene "más manos que aceitar", b) Las privatizaciones de las empresas estatales son una inmejorable ocasión para obtener cuantiosos réditos ilegales, c) Los líderes populistas se valen de su propio carisma y del ímpetu de la ciudadanía para obtener beneficios personales.

Desde otro punto de vista, Brunetti y Weder (1998c) (Estos autores aparecen aquí por primera vez en el trabajo, por lo tanto debe ser 1998 a, suponiendo que exista otro trabajo de los autores de ese año, el cual sería 1998b y así sucesivamente) investigaron el impacto de la democracia en el nivel de corrupción en Corea del Sur, Paraguay y Bolivia a lo largo de los últimos años. Utilizando series de tiempo para el nivel de democracia en los citados países y considerando que los tres estarían desarrollando un Estado democrático recién en la segunda mitad del siglo pasado, los autores habrían encontrado un descenso en el nivel de corrup- ción. Sin embargo, a la hora de estudiar desde esta misma óptica a las ex Repúblicas Soviéticas de Europa del Este, las conclusiones son ambiguas o al menos poco demostrativas. Por último, el estudio demuestra que los indicadores que consideran la posibilidad de los ciudadanos para combatir a la corrupción mediante el control y la participación política, son determinantes de los resultados.

Paldam (1999a), por el contrario, demostró que si bien la relación entre democracia y corrupción es significativa, pierde valor en el momento en que el PBI per capita entra en la ecuación. El autor concluye que el efecto de la democracia con respecto al fenómeno de la corrupción es, al menos, ambiguo.

Si bien Treisman (2000) coincide con Paldam (1999a) en juzgar ambiguo al resultado del citado índice de democracia y corrupción; sin embargo, a partir de una muestra de 64 países encuentra una débil pero marcada tendencia en contra de la corrupción en aquellas democracias de más de 50 años. Aparentemente, si bien el grado momentáneo de democracia no es determinante en la lucha contra la corrupción, sí resulta significativo en las democracias que han podido perdurar en el tiempo. Éste argumento concluye en la misma línea de Brunetti y Weder (1998b).

\subsection{Pérdida de legitimidad}

Una de las consecuencias más evidentes de la corrupción política es la pérdida de legitimidad ante el pueblo que padecen los gobiernos con problemas de corrupción (Rose-Ackerman, 1996; Gray y Kaufmann, 1998; Seligson, 2002). No sorprende demasiado que el estudio 
cuantitativo realizado por Lederman (2001) encontrara evidencia que destaca la importancia de las instituciones políticas en la determinación del nivel de corrupción. Los resultados del trabajo afirman que la democracia, los sistemas políticos parlamentarios y la estabilidad política están directamente relacionados con bajos índices de corrupción.

Por otra parte, según Caciagli (1996), la falta de alternancia de partidos políticos o de coaliciones de partidos puede disminuir el temor al castigo de los funcionarios; así también el poder y la instancia del nombramiento de ciertos cargos muy influyentes puede generar ocasiones de corrupción. También el aumento de los miembros de los partidos políticos hace más altos los costos de la política, lo que da lugar a una mayor necesidad de obtener recursos. Cortina et al. (1996) directamente responsabiliza a la crisis de identidad de los partidos políticos de la crisis de representación y participación política.

Ahondando en esta línea, Trujillo (2002) señala que junto a los partidos políticos y sus funcionarios, también pierde legitimidad la cuestión política en sí, es decir, la política como realidad. También Tanzi y Davoodi (1998) indican el descrédito que sufre la democracia como sistema político en la medida en que la corrupción se va instalando en una sociedad. Por esto mismo, el cargo de funcionario público pierde el reconocimiento positivo del pueblo y su status se degrada. Las consecuencias de esta pérdida de legitimidad son de largo y profundo alcance. Por un lado, el cargo público se convierte en una vocación poco deseada y entre aquellos que aún quieren ocupar cargos públicos cabe esperar una buena cantidad de hombres sin escrúpulos. Por otro lado, la carrera política deja de considerarse como una vocación de servicio para convertirse más bien en un ámbito donde pueden obtenerse beneficios personales muy redituables.

Según Amundsen (1997), la corrupción política implica la manipulación de las instituciones políticas y las reglas de procedimiento a favor del beneficio privado. De esta manera, distorsiona las instituciones del gobierno, desviando los valores que constituyen el Estado Moderno, imponiendo un escenario de decadencia institucional. El problema básico de la corrupción política es la falta de voluntad política para enfrentar el problema: quienes poseen el poder político no pretenden cambiar un sistema del cual son los principales beneficiarios. Ante este hecho, diversos autores han afirmado que la falta de competencia en la carrera pública está relacionada con altos índices de corrupción. Ades y Di Tella (1995) sostienen que el grado de competencia que exista entre los distintos funcionarios públicos determinará el modo de su acción: coalición, monopolio o independencia.

\subsection{El tamaño del Estado}

Entre las diversas causas políticas de la corrupción varios autores atribuyen al tamaño del Estado un papel preponderante (Mauro, 1995; Lambsdorff, 1999a, b; Trujillo, 2002). En los '90, ha sido una preocupación constante el señalar que un Estado grande presenta mayores oportunidades para que funcionarios desleales establezcan demoras innecesarias en los trámites, permisos, habilita- 
ciones, etc., y mediante la aplicación de una cierta discrecionalidad -no siempre fundadas en normativas- obtengan rentas. Según Andvig y Odd-Helge (2000), no siempre un Estado grande significa altos niveles de corrupción y pone como ejemplo a los países nórdicos que con elevados porcentajes de gasto público en relación con el PBI presentan muy buenos puestos en el ranking de Transparency International.

En la Tabla 1 se muestra la relación entre tamaño del Estado ${ }^{2}$ y percepción de Corrupción.

De la Tabla 1 se desprende que Finlandia, tiene un gasto público equivalente al $59.4 \%$ de su PBI, y que en segundo lugar le sigue Dinamarca con un $60.8 \%$. De los países nórdicos, Finlandia, Dinamarca y Suecia (66.1\%), se ubican fuertemente por sobre el promedio de tamaño del Estado de esta muestra (48.0\%). Solamente Noruega (46.4\%) e Islandia (37.3\%) estarían por debajo. EI país con el Estado más pequeño en esta muestra serían los EEUU con un $34.6 \%$, pero debemos también relativizar este resultado porque su economía es la más grande del mundo.

Como explicación a este fenómeno de elevado gasto público y buen desempeño en cuanto a niveles de corrupción en los países nórdicos, deberíamos señalar que la respuesta podría estar por el lado de la cultura política imperante y la naturaleza de los mecanismos de con- trol (Tiihonen, 2003 y Andvig y Odd-Helge, 2000).

\subsection{Eficiencia burocrática}

Paolo Mauro (1995, 1997, 1998) destaca a lo largo de sus investigaciones el papel determinante que ocupa la eficiencia burocrática en la corrupción. Mauro afirma que ésta variable posee una relación inversamente proporcional con el nivel de corrupción. Según el autor, los países que presentan altos niveles de eficiencia burocrática también muestran un alto grado de estabilidad política. Más aún, dicha estabilidad política repercute positivamente en el plano económico favoreciendo la inversión privada en general y en particular de maquinaria pesada. EI PBI per capita también experimenta una tendencia de crecimiento cuando la eficiencia burocrática tiene niveles altos.

Autores como Tanzi y Davoodi (1998) han señalado que el exceso de regulaciones y autorizaciones necesarias para avanzar en trámites es una causa de la corrupción política. Es un hecho descrito en casi todos los estudios sobre corrupción que la sobrerregulación administrativa y la ineficiencia de los procesos burocráticos pueden llevar a los ciudadanos a pagar un soborno para acelerar u obtener aquello que los funcionarios debieran brindar de buena ley.

Según Acemoglu y Verdier (2000), cuando una burocracia se expande por

2 Por tamaño del Estado entenderemos aquí a la relación de gasto público comparada con el PBI del país. Si bien no sería la única forma de medir el tamaño del Estado (por ejemplo: cantidad de agentes públicos sobre la población económicamente activa), de acuerdo a la disponibilidad de los datos, esta forma nos resultado la más accesible. 
Tabla 1. Ranking de corrupción y tamaño del Estado

\begin{tabular}{|c|c|c|c|}
\hline \multirow[t]{2}{*}{ País } & \multicolumn{2}{|c|}{$\begin{array}{l}\text { Ranking en CPI de Transparency } \\
\text { Internacional }\left({ }^{*}\right)\end{array}$} & \multirow[t]{2}{*}{$\begin{array}{l}\text { Tamaño del Estado } \\
\text { (gasto público sobre } \mathrm{PBI})\left(^{* *}\right)\end{array}$} \\
\hline & Puesto & Índice & \\
\hline Finlandia & 1 & 9.7 & 59.4 \\
\hline Dinamarca & 2 & 9.5 & 60.8 \\
\hline Nueva Zelanda & 3 & 9.5 & 42.3 \\
\hline Islandia & 4 & 9.4 & 37.3 \\
\hline Singapur & 5 & 9.3 & 35.0 \\
\hline Suecia & 6 & 9.3 & 66.1 \\
\hline Canadá & 7 & 9.0 & 46.4 \\
\hline Luxemburgo & 8 & 9.0 & 49.3 \\
\hline Holanda & 9 & 9.0 & 58.1 \\
\hline Gran Bretaña & 10 & 8.7 & 43.7 \\
\hline Australia & 11 & 8.6 & 37.5 \\
\hline Noruega & 12 & 8.5 & 46.4 \\
\hline Suiza & 13 & 8.5 & 36.9 \\
\hline Hong Kong & 14 & 8.2 & $S / D$ \\
\hline Austria & 15 & 7.8 & 52.7 \\
\hline Estados Unidos & 16 & 7.7 & 34.6 \\
\hline Promedio & & & 48.0 \\
\hline
\end{tabular}

(*) Fuente: Transparency International, 2002.

$\left({ }^{* *}\right)$ Fuente: Institut Économique de Montréal, 2000.

CPI: Corruption Perceptions Index.

sobre su tamaño máximo óptimo, el número de los empleados públicos crece a tal punto que el desempeño del sector deja de ser eficiente. Incluso, dado que una mayor burocratización implica el crecimiento de presupuesto para el sector, muchos actores del sector privado pretenderán pasar hacia la función pública, aún teniendo fuertes ventajas competitivas en las actividades privadas.

\subsection{Captura del Estado}

Desde hace varios años se ha instalado en el ambiente académico la tematización de un concepto conocido como
"Captura del Estado". Este concepto intenta señalar el hecho de que individuos o empresas pueden aprovechar su poder, influencias, amistades o asociaciones, para condicionar la acción de una agencia estatal mediante la instalación de personas afines en los cargos claves del organismo controlado. De esta forma la agencia pierde su autonomía y sus decisiones finales quedan condicionadas al interés del grupo dominante (Kaufmann y Hellman, 2001).

Cuando la captura del Estado es llevada a cabo por empresas privadas, éstas se esfuerzan en definir las políticas, 
legislaciones y regulaciones del Estado que necesitan para obtener ventajas especiales. Esta forma de utilizar a las instituciones públicas es potencialmente muy peligrosa ya que puede manifestarse desde formas cuasi inocentes de lobby hasta la limitación de competencia y exención impositiva a cambio de pagos ocultos (Reos, 2002).

Varios autores coinciden en que la mejor forma de evitar la "captura" es a través de una profesionalización y estabilidad del personal de las agencias en cuestión. Dado que la permanencia de los funcionarios en los puestos públicos implica una mayor profesionalización, pero al mismo tiempo evita la profusión de contactos con el sector privado, que tendrían lugar si hubiese una elevada rotación laboral entre ambos sectores (Tiihonen, 2003; Andvig y Odd-Helge, 2000; Acemoglu y Verdier, 2000).

\subsection{Funcionamiento de la Justicia}

En el caso del funcionamiento de la justicia, podríamos utilizar una analogía con el concepto del punto anterior, dado que si bien es muy difícil que ciertas empresas intenten una captura del poder judicial, en el caso de los países de baja institucionalización, los sistemas judiciales son fuertemente sensibles a la influencia política y económica de ciertos actores. En la influencia política (Malem Seña, 2002), los mecanismos de nombramiento de jueces muy ligados a criterios de tipo partidistas condicionan fuertemente la independencia de los magistrados. En cuanto a la influencia económica, la misma es ejercida a través de abogados o "lobbistas" pertenecientes a los grandes estudios con fuertes contac- tos con los magistrados, aunque también puede darse una combinación de ambos factores.

La baja institucionalización también implica que los jueces no están verdaderamente concientizados de la importancia institucional de la independencia de su magistratura de criterios extrajudiciales (Rose Ackerman, 2001; Malem Seña, 2002).

Por otra parte, Leys (1970) afirma que una de las causas de corrupción es que la policía y los jueces son poco eficientes y muchas veces responsables de focos de corrupción. El World Development Report de 1997 presentó la evidencia de que en 59 países la falta de predictibilidad del sistema judicial era causa del aumento de los niveles de corrupción. Consecuencias similares entre el desarrollo de la corrupción y la dependencia del sistema judicial son profundizadas por Ades y Di Tella (1996).

Cuando la ley se vuelve parcial, entonces la corrupción ataca el fundamento de la obligación social. En este marco, aquellas acciones que no están prohibidas por la formulación de una ley aparecerían como legítimas. Etkin (1993) señala que éste es el ámbito a través del cual se filtra la corrupción en los sistemas sociales, por ello cree que hay que hablar de norma en un doble sentido, como ley y como grandes principios morales que orientan el accionar humano.

La independencia del poder judicial es prácticamente el único punto sobre el que existe un consenso unánime en la bibliografía consultada. Allí en donde el mecanismo judicial no funciona eficientemente, la corrupción está fuera de control. 


\subsection{Confianza e instituciones}

La importancia que juega la confianza como control de la corrupción es capital (Tapscott, 2001; Sztompka 1997; Fukuyama, 1995). Por un lado, la confianza surge de las relaciones interpersonales sinceras y responsables. Estas son relaciones en las que los diversos actores demuestran lo verdadero y bueno de sus intenciones mediante la transparencia de su accionar. De esta forma, el hombre u actor político que establece contacto voluntario con un semejante, lo hace cediendo o afirmando lo que el otro realmente es y respetándolo. Por otra parte, la confianza tiene la capacidad de irradiarse a toda la comunidad política a través de las distintas instituciones. Desde el núcleo familiar, pasando por la escuela, amigos, ámbito laboral, instituciones participativas intermedias hasta los máximos poderes de un Estado, la confianza es garantía de transparencia en la comunicación y acción entre los hombres, y signo de su sentido de vinculación común con la comunidad política en la cual todos se hayan comprometidos.

El modelo de estructura jerárquica que adopta una sociedad, tendría una relación directa con el grado de confianza que experimentaría. Es decir, si la jerarquía fuera rígida y aislada, los niveles de confianza bajarían ya que los distintos estratos sociales se encontrarían distantes unos de otros, no se conocerían, no se controlarían, tenderían a no involucrarse y a no trabar más relación que la imprescindible. Por el contrario, si la jerarquía fuera flexible y mediada, los niveles de confianza se fortalecerían ya que las distintas partes sociales se reconocerían y reafirmarían su relación efectiva, serían concientes de su destino y responsabilidad compartida; y controlarían su mutuo funcionamiento. Lo que distingue de fondo estas dos concepciones de jerarquía es el concepto de "participación".

En la sociedad política moderna, la idea de "participación política" implica necesariamente instituciones intermedias que oficien de nexos reales entre los ciudadanos y los poderes e instituciones gubernamentales. El funcionamiento de estos nexos debería ser tal que permitiera el contacto fluido, por un lado, de los ciudadanos entre sí y, por el otro, de las instituciones y los ciudadanos. No se trata sin embargo, de construir nuevas estructuras sino de refinar las existentes en cuya raíz se encuentran los medios y propósitos de una buena comunicación entre los hombres (Lambsdorff, 1999a; La Porta et al., 1997).

Cuando las democracias han alcanzado su consolidación, se observan bajos niveles de corrupción en razón de su calidad institucional elevada (políticos representativos, jueces eficientes, organismos de control profesionalizados, sociedad civil activa, etc.). En el caso de las democracias en transición se constata una débil calidad institucional y una baja actividad de la sociedad civil. Por lo tanto, los resultados son, bajos niveles de responsabilidad, confianza, compromiso, eficiencia y subciudadanía.

\subsection{1. ¿Es la corrupción funcional a la política?}

Para algunos autores la corrupción es funcional para la política en tanto facilita el funcionamiento de los sistemas polí- 
ticos y puede ayudar a que un régimen se sostenga $o$ adapte exitosamente. Frente a argumentos de este tipo, Johnston (1986) señala que la corrupción conduce a determinados estados que para ser justamente valorados deberían poderse comparar con escenarios en los que no existiera la corrupción, hecho que resulta difícil de imaginar en sociedades que se han vuelto permeables a las prácticas corruptas. Aún si nos proponemos estudiar situaciones hipotéticas no podríamos realmente decir si la corrupción ayuda o no a que un sistema sobreviva. Como máximo podemos discutir su rol como un proceso que opera en un escenario determinado.

Como alternativa al argumento funcionalista, Johnston (1986) propone estudiar los diferentes tipos de relaciones entre personas y grupos que la corrupción tiende a crear. El autor plantea una matriz con las siguientes variables de análisis: carácter integrador o desintegrador de las prácticas del grupo y; estabilidad o inestabilidad temporal del grupo a lo largo del tiempo.

Por otra parte, cuando Huntington (1968) se refería a las sociedades en cambio, hacía una cierta valoración positiva de la corrupción como un mecanismo que destrababa las rigideces de sistemas que se resistían al cambio. En su momento, esos sistemas eran de índole patrimonialista conservadora y se resistían a la incorporación de innovaciones políticas. Es en ese contexto en el que Huntington imagina una cierta funcionalidad positiva de la corrupción, pero de allí a extrapolar este pensamiento a una recomendación permanente sobre la corrupción como instrumento benéfico, existe una gran distancia.

Muchas experiencia latinoamericanas recientes demostrarían que la corrupción afrenta de tal forma al sistema político que si no es contrarrestada, socava las bases institucionales y degrada el nivel de confianza interpersonal (Sztompka, 1997 y Malem Seña, 2000).

\section{Razones y efectos económicos}

A partir de la explosión del tema corrupción, la literatura económica ha abordado éste fenómeno desde múltiples ópticas. Desde la estructura de costos de la corrupción, pasando por la estructura de incentivos, hasta la modelización del comportamiento individual de ciertos actores ${ }^{3}$.

David Gould y José Amaro-Reyes (1983), investigadores para el Banco Mundial desarrollan, la tesis de la corrosión económica de la corrupción: "La corrupción conduce a la ineficiencia económica y dilapidación debido a su efecto sobre la asignación de recursos, la producción y el consumo. Es improbable que las ganancias obtenidas gracias a los mecanismos de la corrupción se traduzcan en inversiones. El dinero mal habido se utiliza en consumo ostentoso o se transfiere a cuentas bancarias del exterior. Estas transferencias constituyen un drenaje de

3 Para ver una descripción de las perspectivas Principal-Agente, recomendamos consultar a Adam Przeworski (1998). 
capital para la economía doméstica. Además, la corrupción genera ineficiencia en la asignación de recursos cuando permite que el contratista con mayor habilidad para sobornar sea el adjudicatario de los contratos del gobierno. (...) Es muy probable que se originen sistemas perversos que impidan el ingreso del personal más idóneo. Esta situación puede verse aún más agravada cuando por razones morales, empleados potencialmente eficientes no concursan para ocupar puestos en el gobierno".

A partir de los ' 90 los trabajos sobre el tema adquieren herramientas cuantitativas más precisas, la conclusión sigue siendo la misma: La corrupción económica sale cara, produce pérdida de oportunidades, mala elección de proyectos y demora de aquellos que son vitales. Por otra parte, la corrupción desminuye la inversión en educación y desalienta la inversión extranjera (Mauro, 1995). Wei (1997a) y Campos (1999), realizaron estudios econométricos al respecto llegando ambos a la misma conclusión: permaneciendo todos los demás factores constantes, los inversores prefieren invertir en los países que presenten el menor grado de corrupción. Wei (1997b) encuentra que un incremento en el nivel de corrupción de Singapur al nivel de México tiene el mismo efecto económico que un incremento del $20 \%$ en la presión impositiva ${ }^{4}$.

Otros autores (Gray y Kaufman, 1998) centran su estudio en el ámbito del sector público, y luego de una serie de en- cuestas a dirigentes empresarios de 60 países subdesarrollados concluyen en que este tipo de corrupción es el principal obstáculo para el desarrollo de las economías nacionales.

\subsection{Comportamiento rentístico}

La renta económica surge cuando un individuo o empresa posee algo único. Alguien que tiene en su posesión un activo tan especial puede cobrar un precio superior al normal y obtener así una renta económica; es decir, ganancias en exceso a todos los costos relevantes ${ }^{5}$.

El "Rent seeking" o el esfuerzo por adquirir rentas no está necesariamente prohibido por la ley o considerado inmoral por la sociedad; tampoco es necesario que su efecto económico de largo plazo sea negativo si las rentas son reinvertidas productivamente. Pero autores como Mauro (1998), lo consideran directamente improductivo y económicamente ineficiente.

Según Mauro (1998), ya que la última fuente del comportamiento rentístico es la disponibilidad de rentas, "la corrupción probablemente tenga lugar en aquellos países donde las restricciones y la intervención del gobierno permitan la obtención de ganancias excesivas." Como ejemplos, incluye a las restricciones comerciales, las políticas de favoritismo industrial, el control de precios y el control gubernamental de la provisión de crédito.

Por otra parte, algunas rentas pueden surgir dada la ausencia de control es-

4 Estas investigaciones indican que, en los países del Sudeste Asiático, otros factores contrarrestarían la influencia negativa de la corrupción en el desarrollo económico.

5 El típico caso es el de los beneficios económicos obtenidos por los monopolios. 
tatal, como en el caso de los recursos naturales, tales como el petróleo, cuyo suministro está limitado por naturaleza y cuyo costo de extracción y refinamiento es mucho más barato que su precio de mercado. Ya que quienes extraen petróleo tienen la posibilidad de obtener ganancias extraordinarias por las singulares características de este producto, es muy probable que los funcionarios que tienen a su cargo la asignación de los derechos de extracción sean tentados con sobornos (Mauro, 1998).

Por su parte, Reos (2002) señala que la opacidad de información en los mercados desencadenan fallas en la asignación de recursos. Precisamente ésta característica produce oportunidades de rentas económicas. Aquellos que tienen acceso a más información acerca de las acciones de gobierno pueden utilizar esos datos en su beneficio y obtener así una renta. Ya sea que un funcionario tenga el poder de aplicar multas sin necesidad de rendir cuentas a un órgano controlador o que pueda establecer el precio máximo de ciertos productos, el manejo unilateral de la información es ocasión para el comportamiento rentístico.

\subsection{Corrupción en las inversiones públicas}

Según Rose-Ackerman (1996), los sobornos realizados a funcionarios por parte de los potenciales contratistas hacen que los contratos, tanto del gobierno como de las empresas estatales privatizadas, no sean asignados al contratista más eficiente sino al dispuesto a un soborno más alto. Las causas de la consiguiente ineficiencia en el ejercicio de la la- bor del contratista son muchas: el contratista más eficiente puede sentir escrúpulos de participar de prácticas fraudulentas y por ello abstenerse de participar en la licitación; aquel que asume el pago de un soborno esperará obtener subsidios, beneficios monopólicos y regulaciones cada vez menos estrictas; los proyectos pueden volverse más complejos y difíciles de realizar ya que así es más fácil disimular los sobornos; para compensar el pago del soborno el adjudicatario puede bajar la calidad de su servicio o la calidad de los materiales a utilizar para realizar la obra; los procesos pueden demorarse a drede para obtener aún mayores pagos de coimas.

A su vez, Tanzi y Davoodi (1998) consideran que al sector privado le resulta conveniente muchas veces apelar a prácticas corruptas cuando existen regulaciones como permisos y licencias para diversas actividades en poder de funcionarios que las administran en condiciones monopólicas de hecho.

Es interesante señalar que estudios de caso realizados por distintos autores y reunidos por Rose-Ackerman (1996) demuestran que los pagos que se llevan a cabo en los contratos corruptos pueden incrementar los costos y disminuir la calidad de los proyectos públicos de un $30 \%$ a $50 \%$.

Según Tanzi y Davoodi (1998), la corrupción tiene un impacto negativo en la calidad y productividad de la inversión pública. También Mauro (1997) señala que la corrupción origina una merma de las inversiones públicas reales.

Desde otro punto de vista, Gray y Kaufmann (1998) y Busse (1996) han señalado que en el marco de una economía 
con señales de corrupción, existe un aumento de los costos de transacción para el sector privado causado no sólo por los sobornos sino también por las demoras intencionales para llevar adelante los proyectos empresariales. En esta misma línea, la Encuesta de Competitividad Global del Foro Económico Mundial de 1997 demuestra que las empresas que pagan sobornos pasan más tiempo en reuniones y negociaciones con funcionarios públicos, reportando un costo más alto del capital de la empresa. Tanzi y Davoodi (1998) se valen de esta encuesta para desarrollar su investigación y concluir en los mismos resultados que Gray y Kaufmann y Busse.

Por otro lado, Rose-Ackerman (1996) señala que la corrupción favorece la distribución injusta del ingreso ya que para compensar las pérdidas causadas por contratos mal asignados se deberán cobrar impuestos más altos, disminuyendo el gasto en asuntos de necesidad pública. Otros autores (Gupta et al., 1998) además de concluir que la corrupción engendra la disparidad de ingresos (a partir del estudio del coeficiente de Gini en varios países), afirman también que la educación y la distribución de la tierra se ven igualmente afectadas por éste fenómeno.

Según Bai y Wei (2000), la corrupción condiciona las políticas económicas al sesgar la decisión. Gray y Kaufmann (1998) y Shleifer y Vishny (1993) también descubrieron que muchas decisiones de asignación del gasto público pueden verse afectadas por la corrupción; especialmente, en aquellos casos en que se destinan mayores recursos a ciertos sectores debido a las oportunidades de beneficios personales que pudieran brindar dichos sectores. En esta misma línea, la investigación Mauro (1997) encontró evidencia de que el gasto en educación, salud y áreas de mantenimiento y operaciones, se ve reducido por la presencia de corrupción, ya que en éstas áreas es más difícil que quienes toman las decisiones presupuestales puedan obtener una "rebanada de la torta".

Shleifer y Vishny (1993), por su parte, explican el crecimiento de la ineficiencia económica en la Rusia Post-Comunista en comparación con la U.R.S.S. El Partido Comunista centralizaba la recolección de sobornos y monitoreaba efectivamente, con la asistencia de la KGB, cualquier desviación en los patrones de la corrupción. En la actualidad, distintos ministerios y agencias gubernamentales determinan su propia política de sobornos en un intento descentralizador de maximizar sus beneficios. Se suele criticar al Estado Regulador como raíz de la ineficiencia que surge de las distintas regulaciones; pero el estudio de éstos autores sugiere que un gobierno central débil con la consiguiente incapacidad para detener el crecimiento de redes de corrupción independientes, agudiza aún más el problema de la ineficiencia. Reos (2002) llega a la misma conclusión según la cual en Rusia la debilidad institucional de la nueva administración permitió el surgimiento de nuevas formas de corrupción, las cuales a su vez aumentaron los costos económicos por la pérdida de eficiencia en las transacciones.

\subsection{Corrupción en las Finanzas Públicas}

Según Busse (1996), la corrupción altera las políticas públicas tributarias, 
terminando por dar tratos impositivos preferenciales a ciertos sectores a cambio de beneficios particulares. En esta línea, Reos (2002) sostiene que el efecto fundamental de la corrupción en la recaudación de impuestos es una disminución en los recursos del Estado con relación a lo que la legislación autoriza y los órganos de ejecución del presupuesto han previsto obtener. Las leyes de presupuesto tienen la característica de autorizar un máximo en el monto de los gastos del Estado y estimar un valor de lo que se espera recaudar conforme a la legislación impositiva vigente y el nivel de actividad económica proyectado. Mientras que la proyección de la recaudación depende de técnicas estadísticas y de la experiencia económica del país, la autorización de los gastos es efectiva y ésta parte del presupuesto es generalmente alcanzada. De esta manera, cuando las instituciones de recaudación no cumplen sus metas a raíz de la corrupción de sus funcionarios, el Estado padece un déficit. Éste se cubre a expensas del endeudamiento público, es decir, con obligaciones para futuros presupuestos que conllevan un creciente costo financiero con el transcurso del tiempo.

Por otra parte, Reos (2002) afirma que cuando se producen desbalances grandes y continuos en las cuentas del Estado, se generan expectativas negativas en los mercados de capitales internacionales acerca de las perspectivas de estabilidad económica del país. Las agencias calificadoras de riesgo financiero analizan esos desbalances y los toman en cuenta para establecer el nivel de riesgo de los papeles financieros que el país emite. Ese nivel de riesgo está directamente asociado a las tasas de interés que regirán para el futuro, no solamente para la deuda pública sino también para las deudas de empresas privadas. Más aún, las Calificadoras del riesgo-país toman en cuenta puntualmente la percepción de corrupción al elaborar los informes para los potenciales inversores. Cuando hay una percepción de corrupción generalizada en las instituciones públicas, particularmente las vinculadas a la recaudación impositiva y aduanas, esto anticipa las dificultades que tendrán las autoridades económicas para alcanzar estabilidad fiscal y, por lo tanto, para mantener o reducir los niveles de endeudamiento.

En años recientes, han surgido varios estudios que se ocupan de analizar cuantitativamente las relaciones entre corrupción y cuentas fiscales. Friedman (2000), demuestra que aquellos países que tienen un alto nivel de corrupción, se constata una menor incidencia de la recaudación de impuestos como proporción del PBI.

Fons (1999) por su parte, encontró una fuerte relación entre los índices de Transparencia Internacional y las calificaciones del potencial financiero de Moo$d y^{\prime} s^{6}$. En su artículo, demuestra que aquellos países que experimentan índices negativos según los estándares de Transparencia Internacional, poseen también un elevado riesgo de crédito, con evaluar el riesgo y potencial de los bancos. 
el consiguiente crecimiento de la tasas de interés.

\subsection{Empleo y salario}

Evans y Rauch (1996) investigan, en 35 países en desarrollo, el impacto sobre la corrupción que genera la selección de personal basada en estándares de méritos y capacitación. Los autores demuestran que exigir un alto nivel de capacitación a la hora de emplear a un trabajador (posesión de título universitario en general y el haber aprobado un examen formal para ingresar al empleo público en particular) tiende a reducir el nivel de corrupción en la función pública. En lo que respecta a los salarios y su relación con la corrupción, el índice de Evans y Rauch señala una tendencia que sugiere que a salarios más altos se registran menores niveles de corrupción.

Por otro lado, la investigación de Rijckeghem y Weder (1997) afirma que los bajos salarios obligan a los empleados públicos a cubrir sus necesidades de modo ilícito mientras que si el salario fuera alto, la misma actitud implicaría un mayor peligro en caso de ser descubiertos. Analizando estas variables en 28 países, encuentran una importante influencia negativa de los salarios del sector público (en relación con los del sector privado) y los niveles de corrupción. De acuerdo con los autores, el duplicar los salarios del sector público en un país implicaría una mejora de 2 puntos en el índice de percepción de corrupción de Transparencia Internacional. Haque y Sahay (1996) encuentran evidencia en el mismo sentido de Rijckeghem y Weder. Ortiz (1997) y
Mauro (1998) también se hacen de ésta idea como señaláramos más arriba.

Según Acemoglu y Verdier (2000), "con salarios muy bajos todos los burócratas serán corruptos y los oferentes del sector privado recibirán retornos sobre su inversión sólo cuando un funcionario corrupto sea atrapado". Mientras que los salarios de la función pública estén por debajo del nivel necesario para incentivar a los burócratas a ser honestos (o al menos para evitar que la corrupción se vuelva algo necesario para ellos), un aumento salarial tan sólo trasladará individuos al sector y provocará una merma en la producción del sector privado. Las desigualdades de salario entre ambos sectores sólo generan traslado de personal y no resuelven el problema de la corrupción. Mientras que no exista un escalafón de salarios proporcional entre estas dos áreas, la tentación de cometer ilícitos seguirá latente.

\subsection{Riquezas naturales}

Leite y Weidemann (1999) han estudiado la corrupción en países ricos en recursos naturales. Los autores encuentran que estos países son propensos al comportamiento rentístico y consiguientemente a la corrupción. La primera variable de su estudio cuantitativo es el porcentaje de PBI que significan las exportaciones de combustibles y minerales en 72 países. Esta variable es cotejada luego con un índice internacional de corrupción. El resultado señala una marcada tendencia: a mayor participación de éste tipo de exportaciones en el PBI, mayor nivel de corrupción. 
En esta misma línea, la investigación de Gupta y Davoodi (1998) indica que los países ricos en recursos naturales experimentan una mayor inequidad en los ingresos per capita, en la distribución de la tierra y en el acceso a la educación; registrando a la par una baja productividad del capital. Sachs (1995), por su parte, sostiene la mayor lentitud de crecimiento que experimentaría este tipo de países.

\subsection{Comercio Internacional e Inversión Extranjera}

La primera investigación acerca de la relación entre corrupción y comercio internacional corresponde a Hines (1995) quien descubrió una marcada tendencia negativa en las exportaciones norteamericanas hacia países corruptos a partir de 1977. Hines afirma que como los Estados Unidos adquirieron estándares legales estrictos con respecto a sobornos internacionales luego del '77, las exportaciones cayeron como fruto de la competencia poco transparente y desleal por parte de los demás países exportadores.

Lambsdorff (1999b), a su vez, estudió las consecuencias de la corrupción sobre el comercio internacional. La más obvia parece afectar a los bienes que son importados por el sector público. El grado de corrupción entre los funcionarios públicos y los políticos define qué competidor tiene más posibilidades de acceder a un contrato. Esto motiva, por ejemplo, que los permisos portuarios puedan ser falsificados, los trámites de nacionalización evitados, las normas de calidad desatendidas y los contratos concedidos a los exportadores/importadores dispuestos a pagar sobornos más altos.
Aún las importaciones y exportaciones del sector privado - incluso aquellas entre las casas matrices y las subsidiarias de compañías multinacionalespueden verse condicionadas por el grado de corrupción de un país. El nivel de corrupción de los distintos órganos del Estado, responsables de controlar y regular el comercio exterior, depende muchas veces de si el país está dispuesto a compartir prácticas corruptas en orden a obtener ventajas competitivas. En este marco, los empleados del sector privado pueden llegar a solicitar sobornos tanto al gobierno como al exportador/importador a cambio de facilitar algún contrato.

La investigación de Lambsdorff (1999b) incluye en su muestra a los 18 mayores exportadores del mundo y a sus 106 principales importadores. Cada uno de los 18 países exportadores de la muestra obtiene una parte de cada uno de los 106 mercados. En las conclusiones de su trabajo y sin tener en cuenta los idiomas comerciales, la distancia geográfica, la composición de las exportaciones ni los bloques comerciales, Lambsdorff señala que Suecia, como reflejan las percepciones empresariales, está muy poco relacionada con exportaciones corruptas. Sin embargo, esto no quiere decir que no puedan existir en Suecia empresas que incurran en prácticas corruptas para exportar. Pero es de suponer que esto pueda suceder en una medida mucho menor que en otros países tales como Italia, Bélgica, Luxemburgo y Francia; todos países que muestran un marcado índice negativo en lo que hace a corrupción y comercio internacional.

Por otra parte, Wei (1997a) sostiene, a partir de un estudio basado en sig- 
nos econométricos de 100 países, que la corrupción generalmente desalienta la inversión extranjera directa. Mauro (1995) alcanza la misma conclusión. Por otro lado, el estudio de Alesina y Weder (1999) se concentran en el movimiento internacional de recursos para asistencia social. Los autores indican cómo los países Escandinavos tienden a brindar asistencia a países menos corruptos, mientras que los Estados Unidos dan una significativa ayuda a países rankeados como más corruptos.

Al no existir reglas claras y ecuánimes para todos los actores, la corrupción engendra incertidumbre en los distintos tipos de transacciones (Burki y Perri, 1998; Gray y Kaufmann, 1998; Wei, 1997a, b; Shleifer y Vishny, 1993). Estos autores han estudiado las diversas consecuencias que conlleva la corrupción en las reglas que gobiernan las transacciones de un país. Tales consecuencias van desde las dificultades para estimar las relaciones de costo-beneficio de las empresas hasta la disminución en la inversión nacional y extranjera. En esta línea, la investigación de Mauro (1995) arroja resultados significativos: los países corruptos alcanzan un $5 \%$ menos de inversión extranjera que los países no corruptos.

\subsection{PBI y crecimiento}

El impacto de la corrupción sobre el Producto Bruto Interno de un país es uno de los temas más investigados a lo largo de toda la literatura sobre corrupción. Constituye uno de los pocos resultados cuantificados no ambiguos de los estudios sobre corrupción. El nivel del PBI per capita es, sin duda, el indicador que po- see mayor poder explicativo entre los distintos índices que se suelen utilizar para caracterizar éste fenómeno. Husted (1999), por ejemplo, sugiere que el fenómeno de la corrupción está asociado a una baja capacidad productiva.

En cuanto al crecimiento del PBI, según Mauro (1997), las distintas investigaciones acerca del tema permiten concluir en una relación profundamente negativa entre el nivel de corrupción y el crecimiento de un país. A la misma conclusión han llegado otros autores como Leite y Weidman (1999), Poirson (1998) y Keefer y Knack (1995).

Por otra parte, Paldam (1999a) y Lambsdorff (1999a) han cuestionado con inteligencia, si la variable significativa al explicar el crecimiento del PBI es el nivel de corrupción, o si, como algunos trabajos sugieren, la variable determinante es el "cambio" en el nivel de corrupción. Es decir, que en este marco el problema no sería qué nivel de corrupción existe sino que ese nivel permanezca estable. Habría un supuesto subyacente de que ciertas economías no pueden funcionar sin una cierta corrupción, pero tampoco pueden hacerlo en un nivel de corrupción absoluta (Varese, 2001). Queda sin embargo claro que la productividad del capital sufre una caída cuanto más alto es el nivel de corrupción económica.

\subsection{Economías incipientes}

Según Pranab (1997), en la medida en que la economía se expande volviéndose más compleja, los funcionarios públicos encuentran más oportunidades para obtener dinero a partir de sus propias decisiones, las cuales van más allá 
que mantener la ley, el orden y cobrar los impuestos a la renta.

El proceso de transformación de un gobierno totalitario hacia una democracia nos había enseñado los diversos ámbitos fértiles para la corrupción. De modo análogo, la transformación económica que sufren estos países da lugar a prácticas originales de corrupción. Por ejemplo, Europa del Este, China y Vietnam han experimentado el paradójico crecimiento conjunto de la corrupción y del ingreso per capita. Por un período considerable de tiempo, la transformación económica se apoyó en los dos modelos: parte de la producción estaba todavía sujeta a precios fijos mientras que el resto de los productos eran vendidos a precios que determinaba el mercado (Pranab, 1997).

Por su parte, Andvig y Odd-Helge (2000), también considera que los escenarios de transformación económica son particularmente permeables a la corrupción. "La transición desde economías tradicionales basadas en los lazos familiares así como de las economías centralmente planificadas hacia una economía capitalista es más compleja que lo que la mayoría de los científicos sociales pensaban hace una década". El autor afirma que la corrupción surge en momentos en que las sociedades se hallan faltas de lazos de confianza fuertes y carentes de una economía creciente y sustentable.

\subsection{Inflación y economía informal}

Al-Marhubi (2000), encontró evidencia de que existe una relación directamente proporcional entre los niveles altos de la corrupción y la inflación a partir de un estudio de datos cruzados entre varios países. Para desarrollar esta tesis el au- tor tomó en cuenta no sólo el nivel de inflación de dichos países, sino también el nivel de factores asociados a la transparencia, como la independencia del Banco Central y el grado de estabilidad política. También entran en su consideración el nivel de evasión impositiva y el costo de recolección de los impuestos, los cuales tienden a crecer en ambientes corruptos. Aparentemente, también existiría una relación directamente proporcional entre corrupción y economía informal. Esta última sería responsable del crecimiento en la demanda de la moneda local.

También Braun y Di Tella (2000) encuentran una asociación positiva entre corrupción e inflación. Sin embargo, afirman que la inflación engendra corrupción porque dificulta la estabilidad de los precios. A partir de un modelo de institución gubernamental, los autores afirman que los burócratas pueden "inflar" los precios de aquellos tramites necesarios para iniciar un proyecto de inversión. La investigación demuestra la relación directamente proporcional entre corrupción e inflación a partir de una muestra de 75 países a lo largo de 14 años.

A su vez, Johnson et al. (1998) han encontrado que altos niveles de corrupción están en relación con un alto grado de desarrollo de la llamada economía informal. Los autores encuentran que la economía informal ocupa un mayor porcentaje del PBI en países con altos niveles de corrupción y bajos niveles de cumplimiento de la ley. Si bien estos datos se encuadran claramente en economías en transición, al considerar una mayor variedad de países -especialmente los nórdicos- se hace manifiesto que una mayor regulación e impuestos más altos no ne- 
cesariamente aumentan el tamaño de la economía informal.

Aparentemente el problema no sería la regulación y/o los impuestos sino si la administración pública es capaz de operar sin corrupción. Un alto nivel de libertades regulatorias favorece a la corupción y tienden a llevar a las empresas hacia sectores de economía informal. Los autores concluyen en tres puntos fundamentales: a) Los países con más regulaciones tienden a tener una mayor participación de la economía informal en su PBI, b) Los impuestos muy altos a las empresas conducen a un crecimiento de la economía informal, c) Los países con mayores niveles de corrupción suelen mostrar altos niveles de economía informal.

En la misma línea, Friedman (2000) sostiene que es la corrupción, más que las tasas impositivas, el principal determinante del tamaño de la economía clandestina. A partir de un estudio de 69 países, el autor señala que la corrupción percibida parece incrementarse con el aumento de la economía informal. La investigación indica que altas tasas impositivas están asociadas a una mejor recaudación, un ambiente fuertemente legal y una menor actividad clandestina. Sin embargo, los autores señalan la necesidad de detenerse en cómo es administrado el sistema tributario. Rusia es un buen ejemplo de país que posee impuestos medianos pero un sistema de administración impositiva corrupto. Allí hay una gran cantidad de empresas que desarrollan mucha de su actividad en la clandestinidad. Según Andvig y Odd-Helge (2000) probablemente éste sea uno de los principales mecanismos a través de los cuales la corrupción se arraiga en la sociedad.

\subsection{Crisis macroeconómicas}

En países como Albania, Bulgaria y algunos del Este Asiático, las prácticas corruptas en las negociaciones por créditos y, en general, los esquemas financieros poco transparentes parecen haber contribuido a las grandes crisis económicas de esas regiones (Tanzi y Davoodi, 1998). A este ejemplo puede sumarse la reciente crisis Argentina, donde la corrupción parece no sólo haber sido un factor determinante de la crisis sino también de las dificultades que padece el gobierno para recuperar la credibilidad ante el pueblo (Trujillo, 2002).

Según Reos (2002), un aspecto muy importante de la última década ha sido el aumento de la volatilidad de los flujos internacionales de capital que afectó y sigue afectando a las economías de muchos países, especialmente aquellos en vías de desarrollo. A la vez, se ha demostrado empíricamente que la composición de los flujos internacionales de capital está relacionada con la aparición de estadios de crisis macroeconómicas de volatilidad financiera. Así, cuanto menor es la proporción de Inversión Extranjera Directa (IED) en el total de las entradas de capital, tanto más probable es la explosión de una crisis financiera a gran escala.

\subsection{Corrupción y globalización}

Para quienes ligan el incremento de la corrupción en el nivel internacional, al crecimiento del fenómeno de la globalización, no cabe esperar otra tendencia que su crecimiento, es decir, que las dos tendencias irían ligadas (Malem Seña, 2000). Sin embargo, cabría esperar que 
una tendencia mayor a la "transparentación" de los flujos comerciales y financieros internacionales, llevase a una reducción de la corrupción, aún cuando el nivel de comercio se incrementara.

Cuando se observan los rankings de corrupción internacional ${ }^{7}$, y en ellos encontramos que muchos países en vías de desarrollo están al tope de la lista, cabría preguntarnos si toda esa corrupción es endógena, o en parte se debe al proceso de globalización. Para ciertas empresas, es una estrategia válida de acumulación, transgredir todo límite legal en un país no desarrollado buscando la obtención del mayor nivel de ganancias posible. Si realizaran esa práctica en un país desarrollado, serían seguramente penalizados, mientras que en un país pobre, existen muy pocos límites para una estrategia corrupta, es más, se cuenta con múltiples aliados para concretarla. Estos aliados serían políticos y funcionarios locales inescrupulosos, instituciones débiles, o directamente una cultura permisiva y opaca, o de corrupción generalizada. Por ello la idea de corrupción pasiva es sumamente explicativa del efecto de la globalización sobre ciertos países en vías de desarrollo si bien no exculpa completamente a los actores locales.

Uno de los argumentos que usualmente utilizan los organismos multilaterales de crédito para el combate de la corrupción, es justamente la liberalización de los mercados y la libre competencia; mientras más libres sean las transacciones entre y dentro de los países, tanto menores serán los incentivos para las prácticas "opacas". Esta afirmación no es compartida por Malem Seña (2000) quien piensa que no necesariamente los procesos de liberalización implican una mayor "transparentación", porque en economías que permanecieron cerradas, el cambio abrupto en las condiciones de juego, no siempre permite a todos los actores desempeñarse bajo los mismos estándares.

\subsection{Aspectos positivos de la corrupción}

Leff (1964) y Huntington (1968) hacen hincapié en dos aspectos positivos fundamentales de la corrupción: el agilizar los negocios evitando las trabas burocráticas y el introducir un elemento de competencia donde de lo contrario existiría un monopolio. Según Leff "si el gobierno ha errado una decisión, el camino desarrollado por la corrupción bien puede ser mejor". Huntington es aún más crudo: "en términos de crecimiento económico, la única cosa peor que una sociedad con una burocracia centralizada, rígida y deshonesta es una sociedad con una burocracia centralizada, rígida y honesta".

Entre los autores que aún hoy sustentan los beneficios de la corrupción se destacan Beck y Maher (1986) y Lien (1986) quienes, en contraposición a lo expuesto más arriba, afirman que los pagos de sobornos ayudan a asignar proyectos a las firmas más eficientes, ya que estas poseen más excedentes para otorgar "pagos de engrase".

7 Para ver una crítica a las limitaciones analíticas y los sesgos de los índices de corrupción internacional, ver Andvig y Odd Helge (2000). 
Por otra parte, Lui (1985) argumenta que el tiempo tiene diferente valor para diferentes individuos dependiendo de su nivel de ingresos y el costo de oportunidad de su tiempo. Aquellos individuos para los cuales el tiempo es más valioso, estarían dispuestos a pagar sobornos más altos para economizar su tiempo acelerando de este modo los procesos burocráticos. De esta forma, la corrupción aumenta la eficiencia porque ahorra el tiempo de aquellos individuos para los cuales el tiempo es más valioso.

Theobald (1990) discute en su trabajo el punto de vista de varios historiadores que ponderan la influencia positiva de la corrupción a lo largo de la historia. Consideran que un alto nivel de corrupción en la adjudicación de licencias, préstamos y concesiones de tierra y minería ha estado asociados e incluso han ayudado en el surgimiento de la clase empresaria. En la historia Europea, esta clase surgió a partir de la venta de derechos monopólicos y otras formas de acceso privilegiado a los recursos públicos. La corrupción masiva que enmarcó la época dorada de los Estados Unidos entre 1860 y 1870, con amplios registros de casos de corrupción a nivel nacional y federal, aparentemente ayudó al crecimiento económico del país.

\section{Razones y efectos sociales}

En el momento de estudiar el fenómeno de la corrupción, la mayor parte de la literatura especializada no toma en cuenta como prioridad, la dimensión so- cial. Resulta llamativo que la cantidad de trabajos disponibles para el análisis de esta perspectiva sea sensiblemente menor al de las dos primeras; política y económica. Asimismo, es notable lo disperso y escaso de elaboración teórica acerca de la corrupción social. Una explicación posible a esta carencia podría ser la especial dificultad que implica la cuantificación de indicadores sociales ${ }^{8}$ (en lo que respecta a corrupción, los textos académicos tienden a centrar su atención en estudios con un fuerte soporte estadístico). Sin embargo, los escritos que hacen referencia a esta perspectiva, nos brindan indicios válidos en la investigación de distintos aspectos de la corrupción. Así, la reflexión sobre la corrupción social, enfoca diversos temas como la relación entre corrupción y las organizaciones sociales, la religión, el género, la pobreza, la cultura, la composición étnica de la sociedad; elementos que creemos indispensables para una comprensión sistémica e integrada del problema.

\subsection{Actitud culturalista}

Es interesante señalar que ante el fenómeno de la corrupción, como sucediera frente a los diversos problemas que han debido acometer las ciencias políticas, han surgido perspectivas culturalistas que pretendiendo explicar toda la corrupción, sostuvieron como causalidad única a las diferencias culturales. Esta actitud y su tendencia a constituirse en un reduccionismo, ha sido señalada por di- 
versos autores actuales (Trujillo, 2002). Kaufmann (1997) tampoco adhiere a esta vertiente culturalista. En su investigación desaprueba los argumentos del relativismo cultural, al igual que la idea de que sólo es posible controlar la corrupción cuando un país se industrializa completamente ${ }^{9}$.

Por otro lado, la investigación de Andvig y Odd-Helge (2000) pone de manifiesto los problemas que surgen al intentar aplicar un único criterio cultural sobre la corrupción cuando se pretenden estudiar las diversas lógicas sociales que alcanzan a justificar ciertos actos corruptos. Por ejemplo, la distinción occidental entre público y privado resulta inaplicable al contexto indio; en Bengala, por otra parte, muchas formas de soborno no están comprendidas en el concepto "corrupción" y son de hecho lícitas; en Nepal el término "favoritismo" está considerado como una obligación para con la familia y los amigos. Estos ejemplos de Oriente nos demuestran que los comportamientos socialmente aceptados no son los mismos en todos los contextos sino que están culturalmente especificados.

Esta afirmación parece dejarnos ante dos consecuencias posibles: o todo valor es producido en última instancia por la sociedad humana, tendiendo así hacia un relativismo histórico y cultural, o existen valores inmutables que están arraigados en una naturaleza tal que permite que existan matices por los condicionamientos de las distintas culturas. Quizá, como indica el mismo Andvig y Odd-Helge
(2000): "sólo mediante la exploración de la forma en que los actores evalúan sus propias acciones podremos esperar comprender la legitimidad de varias actividades". Es decir, que sólo mediante la reflexión acerca de la responsabilidad personal por sobre las acciones, adquiriremos elementos para juzgar la legitimidad de ciertos actos, de apariencia moral neutra.

Según Varese (2001), en los contextos culturales en los cuales la corrupción está generalizada (pervasive corruption) es muy difícil desarrollar una conceptualización negativa del fenómeno. En estos casos, los condicionamientos culturales funcionarían como un dispositivo de potenciación y estructuración de la corrupción más que un límite, a tal punto que en el texto se relata la experiencia de ciertos funcionarios italianos que llegaron a recibir sobornos sin saber por qué.

\subsection{Incidencia del género}

La relación entre el género y la corrupción ha sido estudiada por Swamy (1999). Su investigación demuestra que ante las mismas situaciones hipotéticas, las mujeres serían más reacias a aceptar sobornos que los hombres. Además, con base en un estudio particularizado, afirma que las empresas cuyas dueños o gerentes son mujeres experimentan una menor percepción de sobornos. Por otra parte, un análisis de datos cruzados de 66 países demuestra que altos niveles de participación política de mujeres estarían asociados a bajos niveles de corrupción. emergente, presentan un menor nivel de corrupción que otros países más industrializados. 
Este estudio constituye la primera evidencia estadística de que: a) La diferencia de género conlleva distintos comportamientos y actitudes frente a la corrupción, y b) Tales diferencias son de suficiente magnitud como para proponer un aumento en la participación política de las mujeres en vistas a reducir los niveles de corrupción. Según Mauro (1995), también es relevante la relación entre mujeres y corrupción. El autor sostiene que el crecimiento del poder social de la mujer reduce los niveles de corrupción.

\subsection{Fraccionalización etnolingüística ${ }^{10}$}

Una de las herramientas cuantitativas para intentar medir algunos aspectos de la corrupción social es el Índice de Fraccionalización Etnolingüística (IFE). Este índice mide la probabilidad de que dos personas tomadas al azar en un país no pertenezcan al mismo grupo etnolingüístico. Por lo tanto, mientras más alto es el nivel del IFE, mayor el grado de fragmentación del país. Mauro (1995) considera que el grado de fraccionalización etnolingüística de un país, no condiciona su ejercicio económico; sin embargo, presenta una relativa influencia en sus efectos sobre la eficiencia y estabilidad institucional. Por ejemplo: el conflicto étnico puede originar un escenario de inestabilidad política y, en casos extremos, guerra civil. La presencia de muchos grupos etnolingüísticos diferentes está también relacionada con una corrupción más dañina y estructural, ya que los políticos de un grupo pueden favorecer a sus pares desatendiendo al resto de la sociedad.

Por su parte, Shleifer y Vishny (1993) sugieren que las sociedades más homogéneas tienen una mayor tendencia a una corrupción de tipo ocasional, que una de tipo estructural. Desde el punto de vista de la estabilidad política, la corrupción estructural sería la más peligrosa.

Este debate nos hacer recordar aquellas ideas enumeradas por Alexis de Tocqueville en la "Democracia en América" (1840) según las cuales una cierta pluralidad en la sociedad oficia como un control competitivo entre las distintas partes. Pero a su vez, este pluralismo tiene un punto óptimo, dado que si se trasforma en fragmentación social, la sociedades que tienen comportamientos estancos, favorecen la corrupción (Varese, 2001).

\subsection{Corrupción y pobreza}

Según Reos (2002), cuando la corrupción se ha transformado en un factor determinante a la hora de tomar decisiones, el tamaño y la complejidad de los proyectos de inversión suelen inclinarse en favor de las propuestas más costosas y opacas. La razón sería que éste tipo de proyecto es de difícil control político. Por lo tanto, se ven favorecidas las oportunidades de corrupción en contratos, nombramientos, consultorías, etc. Tales proyectos pocas veces son utilizados en favor de los pobres. Por su misma naturaleza, no resulta fácil abrir su ejecución a

10 Este índice está construido a partir de los datos de 1960 del Atlas Narodov Mira del Departamento de Geodesia y Cartografía del Comité Estatal Geológico de la URSS. 
grupos de menores ingresos con mano de obra de poca calificación.

En relación con los pequeños o micro emprendimientos, los cuales surgen de los sectores de bajos ingresos, la corrupción suele ser un obstáculo difícil de sortear si pretenden afianzar su crecimiento. Generalmente, la presencia de corrupción administrativa suele expresarse en forma de excesivas regulaciones, controles y trámites para la puesta en funcionamiento del emprendimiento. Ello los afecta en relación con otros emprendimientos de mayor envergadura pero del mismo rubro que no están sujetos a tales controles o que pueden eludirlos a través de pagos ilegales y/o contactos. De este modo, las mayores dificultades para mantener la competitividad de su empresa, terminan por recaer sobre los más pobres (Reos, 2002).

En forma similar, en el área rural los pequeños agricultores, suelen tener limitaciones en las opciones de comercialización de sus cosechas. A menudo, para llegar a los grandes mercados se establecen instituciones públicas de comercialización que actúan como distribuidores de los productos agrícolas. Se argumenta que esas instituciones están creadas para favorecer a los campesinos pobres $y$ evitarles penurias en los mercados más lejanos o con mayor competencia. Como en otros ámbitos, esas entidades tienen también límites en su capacidad de compra y por lo tanto deben racionar los recursos disponibles. Cuando esos centros de comercialización son administrados por funcionarios corruptos, se imponen "tarifas" para efectuar las compras de los productos seleccionados (Reos, 2002).
Por otra parte, Reos (2002) afirma que otra área en donde se producen perjuicios a los pobres, en el marco de la corrupción, es la impositiva. Dado que las legislaciones tributarias son de por sí complicadas y exigen un conocimiento especializado para su interpretación, los pobres tienen menos posibilidades de aprovechar las oportunidades legales para reducir su carga impositiva. En términos relativos, muchas veces la población pobre, paga en forma de impuestos porcentajes más altos de sus ingresos que otros grupos sociales. Mientras que los grupos de ingresos medios o altos tienen a su alcance especialistas en materia tributaria, los pobres muchas veces deben conformarse con pagar montos desproporcionados o directamente dejar de pagar sus impuestos.

Según Tanzi y Davoodi (1998), la distribución del ingreso se ve negativamente afectada por la corrupción ya que permite a personas bien posicionadas y relacionadas aprovechar las actividades del gobierno a expensas del resto de la población, a la vez que diminuye la posibilidad de los pobres de obtener ingresos más altos (Trujillo, 2002).

\subsection{Corrupción organizacional}

Según Suárez et al. (2003) cuando hablamos de corrupción organizacional debemos referirnos a los sistemas de corrupción institucionalizados y no a los actos aislados de corrupción. Ésta distinción resulta fundamental ya que la experiencia señala que a la hora de proponer soluciones a la corrupción, aquéllas que tienen una visión sistémica del problema, 
es decir, que contemplan todas las facetas del fenómeno social institucionalizado, son las que han podido desarrollarse con mayor éxito.

Suárez y Christiensen (2001) afirman que la consideración "corruptor -corrompido" posee un bagaje ético- normativo que dificulta el estudio de los sistemas y procesos de la corrupción. Dicha interpretación engendra "chivos expiatorios" en los cuales se pretende depositar toda la responsabilidad del fenómeno, creando así la ilusión de que si erradicáramos a esas personas se daría solución al problema. Insistir sólo en los actores personales de la corrupción, desvía la atención de la estructura institucional paralela, que oficia como ámbito o espacio de corrupción y que, en última instancia, es la que posibilita la diseminación de la corrupción a toda la estructura social.

Por sistema de corrupción institucionalizada Suárez y Christiensen (2001) entienden a "las estructuras y los procesos que con el tiempo se instalaron en la sociedad como modalidades corrientes de lograr de manera continua beneficios personales a expensas de un bien público". Nos encontramos entonces ante organizaciones cuyas estructuras favorecen el aprendizaje de la operatoria de la corrupción; organizaciones todas con cierta forma legítima que directa o indirectamente ofrece un velo para la impunidad. Estas organizaciones poseen además una forma de coerción, no necesariamente violenta, que desalienta a aque- llos que intentan denunciar el fenómeno corrupto. Por último, la corrupción organizacional se arraigaría en la tendencia de supervivencia corporativa ${ }^{11}$. Es interesante señalar que el proceso de corrupción que gradualmente va admitiendo nuevos miembros se constituye para éstos en garantía de recursos, status o bienes personales.

Además, Suárez y Gorrochategui (1998) encuentran dos elementos actitudinales que facilitan el afianzamiento de la corrupción organizacional: la llamada "moral de frontera" y las "técnicas de neutralización". Según Sutherland y Cressey (1966), la denominada "moral de frontera" es la responsable de ir corriendo los límites normativos, favoreciendo una mayor permisividad social a través de expresiones falaces que son psíquicamente sugestivas pero realmente sin fundamento. ("El lavado de dinero ingresa capitales al país por lo que, en última instancia, es beneficioso para el mismo", "Un poco de corrupción aceita la burocracia", "No controlemos la facturación de esa empresa ya que deja grandes retornos en impuestos", etc.).

David Matza y Sykes (1957), por su parte, desarrolló las llamadas "técnicas de neutralización". Éstas serían las vías a través de las cuales los criminales racionalizarían sus actos, justificándolos finalmente. Los actores de la corrupción tienden a justificar sus acciones en tres grupos de generales de argumentos, a saber: (Fusionar en este párrafo: a, b y c) a)

11 Las organizaciones que el hombre crea, tienden a buscar su supervivencia. En este sentido, es interesante la obra de Gareth Morgan (1999) "Imágenes de la Organización" en la que se hace referencia a la metáfora biológica y orgánica. 
Justifican su inocencia en que las leyes que los juzgan son tan criminales como ellos, b) Niegan haber quebrantado una ley ya que ésta es injusta y por ende, inválida y c) Justifican su accionar en que todos lo hacen.

Suárez et al. (2003), por otro lado, valiéndose de la distinción de Heindenheimer $(2001)^{12}$, intenta delimitar el rango de aceptabilidad y afianzamiento que posee la corrupción organizacional. Suárez et al. (2003) sostienen que la corrupción se institucionaliza cuando se integra a la cultura organizacional y pasa a constituirse en parte radical de nuestras creencias. Desde el punto de vista de la estructura organizacional que favorece la corrupción y, siguiendo el criterio de Heindenheimer, la corrupción organizacional sería de la clase "corrupción blanca".

Desde otro punto de vista, Etkin (1993), sostiene que la corrupción es una de las manifestaciones de la naturaleza contradictoria de las instituciones humanas. Dicha contradicción tiene origen en la complejidad que generan los distintos factores que componen a toda organización. Un ejemplo de esta contradicción está en que nos encontramos en la realidad con organizaciones que formalmente respetan el marco legal vigente pero que cometen acciones corruptas "perversas". Otro ejemplo nos viene dado por el ámbito empresarial en el cual optimizar un área de trabajo implica siempre un costo para otra área; es decir, no hay acción sin consecuencias colaterales. Aún si se intentan homogeneizar los efectos de una acción sobre las distintas áreas de la empresa, chocamos con la tendencia "natural" que experimentan los diversos actores organizacionales, de padecer los cambios desigualmente.

\subsection{Religión y corrupción}

Algunos autores han investigado la relación entre las diversas religiones y el nivel de corrupción de sus fieles (La Porta et al., 1997). El autor considera que las religiones Católica, Ortodoxa y Musulmana, en virtud de su organización particularmente jerárquica, inhiben el desarrollo de una cultura cívica participativa, factor determinante en el control de la corrupción. A partir de una muestra de 33 países, La Porta et al., (1997) proponen la relación directa que existiría entre el porcentaje de los fieles que pertenecen a religiones jerárquicas y la corrupción, en los países donde está presente ese credo en forma mayoritaria. Sin embargo, en una muestra posterior de 114 países (La Porta et al., 1999) la relación se debilita en el instante en que ingresa a la ecuación el PBI per capita.

Por otra parte, Husted (1999) se vale de indicadores de valores culturales para alcanzar una conclusión muy similar a La Porta y Álvarez (1997), es decir, que las estructuras muy jerarquizadas son propensas a la corrupción. Una de las va-

12 Heindenheimer (2001) ha propuesto una caracterización de tres tipos de corrupción: a)“Corrupción blanca”, aquella corrupción que está inculturada, b)“Corrupción negra”, la que toda la sociedad censura, y c) “Corrupción gris", la corrupción que es aceptada por unos y rechazada por otros. 
riables más importantes de su estudio, "Distancia del Poder", es definida como "la medida en que los miembros menos poderosos de las instituciones y organizaciones dentro de un país esperan y aceptan que el poder esté distribuido desigualmente". En esta línea, Lambsdorff (1999b) sostiene que la baja accesibilidad a personas de mayor jerarquía es también causa de la corrupción. Es decir que cuanto más grande es la distancia administrativa, psíquica y real entre un ciudadano común y la autoridad, tanto mayor es el riesgo de corrupción. Desde la mayoría de las investigaciones, brota nuevamente la necesidad de una participación política fluida, secundada por instituciones que oficien de intermediarias entre las distintas partes de la sociedad para realizar una política anticorrupción.

Treisman (2000) también obtiene en su investigación una fuerte relación entre los distintos credos y la corrupción. A partir de una muestra de 64 países, el autor encuentra que donde el Protestantismo es la principal religión, se percibe un menor nivel de corrupción que en los países no Protestantes, aún incluyendo en la ecuación la variable del PBI per capita. Paldam (1999b), por su parte, propone 11 grupos de religiones y coteja cada uno con diversas variables y su impacto sobre la corrupción. Sus resultados coinciden con los de Treisman ya que los países de religiones Tribales y Protestantes experimentarían un menor nivel de corrupción que los Católicos, Musulmanes, Budistas e Hinduistas. Cabe destacar que las conclusiones de Paldam, sostienen la tesis que desarrollara Max Weber respecto a que el carácter político de los Calvinistas se encuentra estrechamente unido a su religión. Según Weber, los Protestantes en general y los Calvinistas en particular, asociarían al cristiano practicante y comprometido, con un buen ciudadano (Weber, 1991).

\subsection{La falta de transparencia en la información}

La mayor parte de los trabajos sobre corrupción destacan como una de sus causas más nocivas a la falta de transparencia informativa; de hecho, hablan de la "opacidad de la información". Tal opacidad comprende a las distintas actitudes morales y estructurales que tergiversan la reproducción fiel de la realidad. Algunos autores interpretan esta opacidad como consecuencia de una crisis anterior de la libertad de expresión (Cortina et al., 1996). Muchos investigadores consideran que los medios de comunicación actuales desvirtúan su vocación de asistir en la formación de opinión ya que exponen mentiras o noticias no confirmadas, $y$ orientan sus esfuerzos en la creación de valores que pueden ser engañosos.

En lo que respecta a estudios cuantitativos, Brunetti y Weder (1998b) indican que una prensa parcial y condicionada por poderes políticos y económicos incentivaría la corrupción. Cuando estamos en presencia de medios que no respetan "ni siquiera un tono de objetividad" y accionan como actores políticos, la confiabilidad de la información es débil y, por lo tanto, se afecta la transparencia del sistema en su conjunto.

En una versión revisada de la investigación anterior, los autores concluyen que la prensa independiente puede tener un fuerte papel de control de la co- 
rrupción. Por ejemplo, en el caso de la Federación Rusa, una prensa independiente que velara por la transparencia, significaría una reducción de la corrupción al nivel de Austria; para Turquía significaría alcanzar el nivel de transparencia del Reino Unido; y para Nigeria el nivel de Francia (Brunetti y Weder, 1999).

Por otra parte, Reos (2002) afirma que el acceso a la información sobre las acciones del gobierno es parte fundamental del carácter democrático de una sociedad. Esta información tiene el carácter de un bien público, es decir, un bien de todos y del que todos son responsables en la proporción en que incidan sobre dicho bien. Como tal bien público, tiene las cualidades de no-exclusión y no-rivalidad. Por no-exclusión se entiende que este bien público es tal que no puede excluirse a nadie de su uso o aprovechamiento. La nota de no-rivalidad significa que el bien público en cuestión puede ser compartido por otros en iguales o diversas proporciones sin perjuicios para ninguna de las partes.

\subsection{Corrupción activa y pasiva}

En el "juego de la corrupción" existen dos actores (corruptor y corrompido) pero habría que introducir la noción de corrupción pasiva y activa. En una época en la que -en virtud de la globalización-se conectan de una forma casi total, actores económicamente disímiles en sus escalas (grandes empresas con pequeños gobiernos, o grandes empresas multinacionales con pequeñas) la introducción de "vicios o abusos de poder o corrupción" no sería una práctica a descartar, como estrategia de adaptación o de acumulación de ciertos actores; o como gesto desesperado de supervivencia.

Al hablar de corrupción pasiva y activa estamos haciendo referencia a las asimetrías de poder (económico, político y cultural) entre naciones. La corrupción afecta al sistema de decisión de las naciones, y como tal, la racionalidad imperante no será el beneficio del mayor número, sino la "satisfacción" de una determinada red de corrupción con su clientela. La ecuación democrática formal que implicaba que un hombre es igual a un voto, se ve nuevamente desequilibra$\mathrm{da}^{13}$, dado que la decisión estaría sesgada por los factores "opacos". En este esquema, la corrupción transformaría a los ciudadanos en "incompetentes políticos" (Malem Seña, 2000). Esta constatación lleva a ciertos sectores ciudadanos a desconfiar de la "cosa pública", con lo cual se repliegan sobre lo privado, dejando el escenario más despejado aún para aquellos que pretenden servirse de las instituciones públicas en su propio beneficio ${ }^{14}$. La corrupción y la desmovilización ciuda-

13 La democracia política formal, tiene una cierta tendencia hacia la igualación (Held, 1996), mientras que los mecanismos de mercado tienden hacia la desigualdad, dado que no es lo mismo un cliente que compra por un millón que aquel que compra por un peso. Esta tensión entre sistema político y capitalismo, ha convivido siempre en la democracia moderna y ha encontrado puntos de equilibrio con distintos niveles de éxito (Estado de Bienestar Keynesiano) según el caso nacional analizado. Según Claus Offe (1990) en ciertos momentos de crisis, esta tensión, puede llevar a que el capitalismo deje de ser democrático o que la democracia deje de ser capitalista. 
dana serían dos fenómenos concomitantes en el orden político.

\subsection{Corrupción y confianza}

Francis Fukuyama (1995) sostiene que el bienestar de una nación, así como su habilidad para competir en el mundo, está condicionado por una única característica cultural que es permeable a toda la comunidad política: el nivel de confianza inherente en la sociedad. Niveles altos de confianza están directamente relacionados con bajos costos administrativos y una marcada confiabilidad institucional. Una sociedad con fuertes lazos de confianza interpersonal generará transitivamente instituciones confiables. En éstas condiciones, se vuelve innecesario un control sofocante de los agentes gubernamentales.

Por otra parte, Fukuyama (1995) considera que las desventajas que experimentan las sociedades con bajos niveles de confianza son fundamentalmente dos: a) Corrupción y comercio condicionado por influencias corruptas, y b) Organizaciones poco representativas e ineficientes.

Adentrándose en la problemática de la confianza, Piotr Sztompka (1997) afirma que la medida de la confianza que los hombres tienen en sus pares y en las instituciones depende de tres elementos: 1) "La confianza reflejada" de modo más o menos racional entre hombres e instituciones, 2) "La confianza básica" que surge desde la socialización en la vida familiar y del conjunto de experiencias en las que se ha confiado en otros; y 3) "La cultura de la confianza" que atraviesa las raíces de la sociedad generando un marco normativo para cada individuo.

Con base en esta distinción, Sztompka (1997) señala las características de una "Cultura de la Confianza" y una "Cultura de la Desconfianza". Cada nota intenta describir las consecuencias que una y otra cultura ejercen sobre la sociedad, ver Cuadro 1.

Por su parte, Reos (2002) afirma que la posibilidad de acceder a información acerca de las distintas actividades del Estado genera condiciones de confianza en la sociedad y en el clima de los negocios, reduciendo los costos de transacción de las empresas. Por el contrario, la falta de información o la sensación de que ésta es incompleta, genera desconfianza en los mercados y afecta negativamente los costos que implican llevar adelante un negocio.

Suárez y Gorrochategui (1998) argumentan que la crisis cultural y de valores que padecen las sociedades pone en jaque la moralidad personal y dejan el campo abierto para su progresiva corrosión. En el hogar, la escuela, la iglesia, el niño aprende una serie de valores que intentan ser consecuentes entre sí. Con el

14 En el caso de la crisis institucional argentina del 2001, surgieron las asambleas barriales en las grandes ciudades que eran una forma de los ciudadanos de participar y de autoconvocarse. Uno de los argumentos que surgió en varias de estas asambleas estaba ligado a la idea de participación como forma de preservar un espacio que había quedado ocupado por malos dirigentes. La idea podría resumirse así: "si participamos, nuestro espacio no puede ser ocupado por personas que no representan nuestros intereses". 


\section{Cuadro 1. Cultura de la confianza y desconfianza}

\section{Cultura de la Confianza}

Libera y moviliza el obrar humano: estimula la creatividad, desinhibición y emprendimiento.

Estimula la sociabilidad y la participación con otros, enriqueciendo de este modo la red de lazos interpersonales.

Estimula la tolerancia.

Refuerza los vínculos del individuo con la comunidad (familia, nación, iglesia) contribuyendo al sentimiento de identidad y generando lazos colectivos solidarios

Reduce los costos de transacción y aumenta las oportunidades de cooperación. La confianza preserva una considerable cantidad de energía social que de otro modo sería invertida en controles.

Fuente: Sztompka (1997).

tiempo, el joven descubre que muchas de las actividades del mundo se desarrollan sobre una sutil traición de la confianza. Se da cuenta además de que "la mayor parte de la propaganda exagera y hasta en algún punto es totalmente falta de confianza". La sensibilidad moral de este joven se vuelve entonces permeable a las distintas formas de corrupción gestándose la "moral de frontera".

\section{Conclusiones}

Estas conclusiones intentan reflexionar sobre las líneas generales de los distintos trabajos estudiados, sin entrar en los disensos que surgieran entre los autores a raíz de cuestiones específicas. Para elaborarlas, nos valimos de una perspectiva sistémica (Bunge, 1999), de modo de mantener una visión general del

\section{Cultura de la Desconfianza}

Paraliza el obrar humano, induciendo conductas conformistas, pasivas o meramente adaptativas.

Erosiona el capital social, atomizando la red de relaciones interpersonales.

Favorece actitudes defensivas, hostiles y prejuiciosas.

Aliena al individuo incitando la búsqueda de identidades alternativas.

Aumenta los costos de transacción dada la constante necesidad de vigilar al otro.

fenómeno corrupción y teniendo en cuenta, a la vez, tanto al agente individual como a la estructura social de la que forma parte.

Dada la complejidad del fenómeno de la corrupción, creemos que la mejor forma de abordar una eventual salida es a través de una mirada interdisciplinaria. Esto implica, desde una reflexión profunda en la lógica intrínseca del fenómeno, hasta la consideración sobre sus consecuencias más prácticas.

Un problema poco tratado en la literatura acerca de corrupción, es la patente dificultad de establecer una relación causal lineal entre las razones y los efectos de este fenómeno. Esta dificultad es significante, ya que su esclarecimiento colaboraría directamente en la elaboración de propuestas más efectivas para atacar el problema, o bien, si el fenómeno no resul- 
tara lineal, nos daría el indicio de que podría obrar bajo patrones recurrentes o círculos viciosos.

El problema es que a simple vista, parecería que todas las manifestaciones corruptas pueden ser a su vez causa 0 consecuencia del fenómeno. Es necesario, para aclarar esta paradoja, distinguir los distintos niveles de realidad en los que existe la corrupción y ser rigurosos en nuestro razonamiento, a fin de evitar cualquier traspaso de orden que pudiéramos haber realizado. Por esto, creemos que es significante utilizar la distinción que hicieran Grondona (1993) y Galli (1996) entre "actos de corrupción" y "estado de corrupción". Por el primer concepto, los autores se refieren a la corrupción cotidiana, por el segundo, entienden a una estructura o sistema que afecta al conjunto de la esfera pública y social.

La corrupción surge con mayor probabilidad, en realidades que están experimentando algún tipo de cambio, transición o crisis. Esto puede ser tanto un Estado que desde un gobierno autoritario pasa a uno democrático, o una economía planificada que intenta transformase en una de tipo capitalista, o una institución que se nacionaliza o privatiza, o un área de la administración pública que transforma su escalafón, o una agencia gubernamental que cambia su legislación, etc. Concretamente, lo que la corrupción parece aprovechar, es el momento en que las reglas no son del todo claras, ya que se está obrando alguna forma de transición. Este momento de interrogantes acerca de cómo llevar a cabo lo que se pretende realizar, resulta una ocasión permeable a las influencias opacas que parecen ofrecer soluciones rápidas. Los escenarios de cambio permanente, en consecuencia, son especialmente proclives a experimentar un mayor nivel de corrupción.

Valiéndonos de la dura metáfora de distintos autores (Baudrillard, 1991 y Etkin, 1993) podríamos afirmar que la corrupción opera como un cáncer en los Estados, instituciones o personas. Es decir, que la misma implica el desarrollo desordenado de algún aspecto del sistema de relaciones interpersonales o de la persona consigo misma. La corrupción se vale de las "fisuras de opacidad" que encuentra en estos sistemas de relaciones y, de alguna forma, anida en ellos comenzado su desarrollo progresivo. Estas "fisuras de opacidad" serían las grietas estructurales de las que se vale la corrupción para llegar al centro del sistema. Además, estas fisuras tendrían la particularidad de velar su presencia y profundidad al espectador común, de modo que una práctica perversa pudiera verse encubierta con la imagen de un perfecto cumplimiento del marco legal (Etkin, 1993). Una vez que la corrupción llegara al eje del sistema, todo el núcleo de relaciones se vería afectado por el mal, así como cada práctica fraudulenta tendería a asimilar también la opacidad contagiada. La peor corrupción sería, entonces, aquella que asimila la lógica del sistema en el cual se instala.

Cabe señalar que las instituciones que el hombre crea adquieren una cierta tendencia por sobrevivir. La corrupción que, valiéndonos de otra metáfora biológica, parasita éstas instituciones, adquiriría también esa cierta tensión por permanecer. De algún modo, la institución se protege para no desaparecer e idéntica 
tendencia adopta la corrupción (Etkin, 1993).

Creemos haber encontrado, al menos cinco factores estructurales, que darían forma a los "estados de corrupción". Estos cinco factores no intentan explicar exhaustivamente toda la realidad del fenómeno corrupción. Sin embargo, consideramos que su interacción orgánica o sistémica puede apreciarse en las realidades que padecen corrupción, Estos elementos serían:

a. Concentración de poder y riquezas asociadas a la impunidad. En aquellos casos en los cuales se constatan grandes acumulaciones de poder y riquezas, acompañadas de la sensación de estar "por encima de la ley", la corrupción suele ser un producto esperable.

b. Profundización de las desigualdades sociales tanto en lo material como en los derechos (tener y poder) o en los saberes. En aquellos contextos en los que se disparan las desigualdades simbólicas y materiales, la corrupción puede ser otro producto esperable además de la aparición de cierta "violencia social" simbólica o física. Cierto tipo de corrupción implica cierto nivel de violencia -sutil o evidente- dado que se afectan los mecanismos de decisión social, se alteran los objetivos públicos y se desvían cuantiosos fondos de sus aplicaciones efectivas.

c. La racionalidad instrumental / Eficientismo / Pragmatismo. Una característica de la modernidad ha sido la racionalidad de tipo técnica que no delibera respecto de los fines últimos de la acción humana, sino sobre la "viabilidad técnica" de una decisión. Esto ha llevado a un afianzamiento del pragmatismo o eficientismo como medida de valor de la acción humana. Todo aquello que sea "práctico o eficiente" es automáticamente bueno, sin deliberar respecto de su bondad o maldad respecto de ciertos fines morales o normativos. Por ello resulta central poner en cuestión a la racionalidad instrumental y adoptar criterios de evaluación de valor más amplios para las decisiones de tipo "técnicas o científicas" que tengan en cuenta un horizonte ético o moral.

d. La caída de ciertos valores como fundamento de las decisiones públicas / Tecnocracia. Ligado al punto anterior, encontramos el fenómeno del fundamento de la decisión pública. Criterios como "bien público" o "bienestar general" o "bien común" no son contemplados por el esquema de decisiones de tipo "tecnocrático" que centra su motivación en la "utilidad pública" medida únicamente en términos de costo-beneficios. La mirada del largo plazo para ciertas sociedades en ahogos financieros, suele ser un lujo de difícil alcance, y en virtud del contexto económico crítico, las recetas tecnocráticas aparecerían como las que tienen un mayor fundamento y realismo. Es necesario volver a deliberar sobre la finalidad de las decisiones públicas, respecto de qué se busca conseguir y a quiénes se busca beneficiar realmente.

e. Egoísmo / Individualismo / Razón Individual. Este punto es especialmente sensible, dado que cierto individualismo extremo que no se concibe como parte de un todo social y para 
quienes en función de una "razón individual" buscan estrategias maximización de sus beneficios sin importar los costos que se le ocasiona a otros. Estas acciones suelen ser el mejor incentivo para la búsqueda de "atajos" para lograr los objetivos individuales que, muchas veces suelen adoptar a la corrupción como estrategia. Según Malem Seña (2000) en un sistema en que los individuos miden su éxito en la vida por la acumulación individual de riquezas o poder, el "atajo" suele ser el camino adoptado por aquellos que se sienten fuera de la carrera.

Todos estos elementos, creemos, que interactúan de una forma sistémica y permiten o impiden el funcionamiento de la corrupción. Con lo cual para proponer una estrategia contra la corrupción, creemos que deben tenerse en cuenta los múltiples elementos que interactúan y el tipo de relaciones que se establece entre ellos. La estrategia de atacar a los "grandes corruptos" tiene un efecto escaso si no se combate el "sistema" o incentivos que los generan. Por otro lado, estimamos que los factores culturales son uno de los condicionantes de mayor peso para un eficaz combate de la corrupción.

No quisiéramos finalizar este trabajo, sin antes sugerir algunas líneas de combate contra la corrupción, que surgen como "comunes denominadores" o consensos del análisis de la literatura especializada:

La transparencia: las condiciones de opacidad son favorables para el desarrollo de la corrupción, por ello todo sistema que pretenda controlarla, debe incrementar las condiciones de transparencia.
Los incentivos: los incentivos son un elemento clave para fomentar o reducir la corrupción desde un punto de vista sistémico. Se debe prestar especial atención a aquellos incentivos de tipo virtuoso.

Los enfoques sistémicos: las visiones reduccionistas de la corrupción suelen ser contraproducentes. El fenómeno tiene características sistémicas, y por lo tanto para buscar controlarla eficazmente, se debe tener una visión de conjunto de su funcionamiento.

Las estructuras que desalientan los usos corruptos: en las estructuras sumamente jerárquicas o que tienen una gran distancias entre las instancias más altas y las más bajas, suelen tener una alta vulnerabilidad a la corrupción. Las estructuras jerárquicas medianas y con un carácter abierto y participativo suelen ser sus mejores antídotos.

Campañas de educación en valores: Uno de los mejores antídotos contra la corrupción es el reforzamiento de los valores sociales positivos. En aquellas culturas en las cuales la corrupción es vista como algo "normal" o "inevitable" es en el contexto en el que su combate resultará más difícil. Si las percepciones sociales son funcionales a la corrupción, resultará imposible sentar las bases para una cultura más transparente.

Fomentar los vínculos de confianza: en las sociedades en las cuales no hay confianza interpersonal entre sus miembros, la corrupción puede ser de tipo "pervasiva". Por ello, el incremento de la confiabilidad interpersonal y de la calidad de las instituciones resulta un elemento clave para el establecimiento de una "cultura de la confianza". 


\section{Referencias Bibliográficas}

Acemoglu, Daron y Thierry Verdier (2000), "The Choice Between Market Failures and Corruption". The American Economic Review, 194-211.

Ades, Alberto. y Rafael Di Tella (1995), "Competition and Corruption". Draft Paper, Keble College, Oxford University.

Ades, Alberto. y Rafael Di Tella (1996), "The Causes and Consequences of Corruption: a Review of Recent Empirical Contributions" en Harris-White, B y White, G. (Eds.) Liberalization and the New Corruption. Brighton: Institute of Development Studies Bulletin, XXVII, 6-12.

Alesina, Alberto y Beatrice Weder (1999), "Do Corrupt Governments Receive Less Foreign Aid?". National Bureau of Economic Research Working Paper 7108, Cambridge.

Al-Marhubi, Fayad (2000), "Corruption and Inflation", Economics Letters, LXVI (2), 199-202.

Amundsen, Inge (1997), "In Search of a Counter-Force. State Power and Civil Society in the Struggle for Democracy in Africa". Unpublished Ph. D. Thesis. Tromsø Institute of Social Science, University of Tromsø.

Amundsen, Inge. (1999), "Political Corruption: An Introduction to The Issues". Working Paper 99:7, Michelsen Institute.

Andvig, Jens \& Fjelstad Odd-Helge (2000), "Research on Corruption: A Policy Oriented Survey". Michelson Institute y Norweigan Institute of International Affairs.

Bai, Chong y Shang-Jin Wei (2000), Corruption: Political Determinants and Macroeconomic Effects. University of Chicago.

Banfield, Edward C. (1979), "Corruption as A Feature of Governmental Organization" en Ekpo, M. (Ed.) Bureaucratic
Corruption in Sub-Saharan Africa. Washington D.C., University Press of America.

Baudrillard, Jean (1991), La Transparencia del Mal. Barcelona, Editorial Anagrama.

Beck, P. y Maher, M. (1986), "A Comparison of Bribery and Bidding in Thin Markets". Economics Letters, Vol. 20, 1-5.

Braun, Miguel y Rafael Di Tella (2000), "Inflation and Corruption". Harvard Business School Working Paper.

Brunetti, Aymo y Beatrice Weder (1998a), "A Free Press is Bad News for Corruption". Wirtschaftswissenschaftliches Zentrum der Universität Basel Discussion Paper, N 9809.

Brunetti, Aymo y Beatrice Weder (1998b), Explaining Corruption. University of Saarland and University of Basel.

Brunetti, Aymo y Beatrice Weder (1999), A Free Press is Bad News for Corruption. Revised Version, Wirtschaftswissenschaftliches Zentrum der Universität Basel.

Bunge, Mario (1999), La Filosofía en las Ciencias Sociales. Barcelona, Editorial Siglo XXI.

Burki, Shaidh y Guillermo Perry (1998), Beyond the Washington Consensus: Institutions Matter. World Bank Working Paper.

Busse, Lawrence (1996), The Perception of Corruption: A Market Discipline Approach. Emory University, Atlanta.

Caciagli, Mario (1996), Clientelismo, Corrupción y Criminalidad Organizada. Centro de Estudios Constitucionales, Madrid.

Campos, Edgardo (1999), "The Impact of Corruption on Investment: Predictability Matters". World Development. 27, 1059-67.

Chull Shin, Don (1994), "On the Third Wave of Democratization". World Politics, 47.

Cortina, A., Peces Barba, G., Velasco, D., Zarzalejos, J.A. (1996) "Corrupción y Ética". 
Cuadernos de Teología Deusto, Nㅜ 9 , Bilbao, Artes Gráficas Rontegui.

Doig, Alan y Theobald, Robin (2000), Corruption and Democratization. London, Frank Cass.

Etkin, Jorge (1993), La Doble Moral de las Organizaciones: Los Sistemas Perversos y la Corrupción Institucionalizada. Madrid, Editorial Mac Graw Hill.

Evans, Peter y Rauch, James (1996), Bureaucratic Structures and Economic Performance in Less Developed Countries, University of San Diego. San Diego.

Fishman, R. y Gatti, R. (2000), "Decentralization and Corruption: Evidence Across Countries". World Bank Policy Research Working Paper 2290.

Fons, Jerome (1999), "Improving Transparency in Asian Banking System". Transparency International.

Friedman, Eric (2000), "Dodging the Grabbing Hand: The Determinants of Unofficial Activities in 69 Countries". Journal of Public Economics, Vol. 76.

Friedrich, Carl (1989), "Corruption Concepts in Historical Perspectives" en Heindenheimer, Arnold (Eds.) Political Corruption. A Handbook. New Brunswick, Transaction Publishers.

Fukuyama, Francis (1995), Trust: The Social Virtues and the Creation of Prosperity. New York, Free Press.

Fukuyama, Francis (1998), "Women and the Evolution of World Politics". Foreign Affairs, Vol. 77.

Galli, Carlos María (1996), "La Corrupción Como Pecado Social". En G. Farrel D. García Delgado - F. Forni; Argentina, Tiempo de Cambios. Buenos Aires. Ediciones San Pablo.

Gould, D. y Amaro-Reyes, J. (1983), "The Effect of Corruption in Administrative Performance: Ilustrations from Developing Countries". World Bank Working Paper $\mathrm{N}^{\circ} 580$.
Gray, C. y Daniel Kaufman (1998), "Corruption and Development". Finance and Development, $\mathrm{N}^{\circ} 35$.

Grondona, Mariano (1993), La Corrupción. Buenos Aires. Planeta.

Gupta, S., Davoodi, H., Alonso-Terme, R. (1998), "Does Corruption Affect Income Inequality and Poverty?" International Monetary Found Working Paper, 98/76.

Habermas, Jurgen (1998), ¿Aprendemos de las Catástrofes? Diagnóstico y Retrospectiva de Nuestro Breve Siglo $\mathbf{X X}$. Ensayo de Jürgen Habermas leído en la Universidad de Magdeburgo. Extractado de la revista Nexos y copiado de El Mercurio.

Haque, Nadeem y Ratna SAHAY (1996), "Do Government Wage Cuts Close Budget Deficits? Costs of Corruption". International Monetary Found Staff Papers, 43, 4: 754-778.

Heindenheimer, Arnold (1990), Topografía de la Corrupción. Investigaciones en una Perspectiva Comparada. St. Louis, Washington University.

Heindenheimer, Arnold (2001), "Disjunctions Between Corruption and Democracy? A Qualitative Exploration". American Political Science Association, San Francisco.

Held, David (1996), Modelos de Democracia. Buenos Aires, Editorial Alianza.

Hines, J.R. (1995), "Forbidden Payment: Foreign Bribery and American Business after 1977". National Bureau of Economic Research Working Paper 5266, Cambridge.

Hope, K. (2000), "Corruption and Development in Africa" en Kempe Ronald Hope y Bornwell Chikulu (Eds.) Corruption and Development in Africa. Lessons From Country Case-Studies. New York, St. Martin Press. 
Huntington, Samuel (1968), Political Order in Changing Societies. Connecticut, Yale University Press.

Husted, B. (1999), "Wealth, Culture and Corruption". Journal of International Business Studies, XXX, 339-360.

Huther, Jeffrey y Anwar SHAH (2000), "Anticorruption Policies and Programs: A Framework for Evaluation". World Bank Policy Working Paper 2501.

ledm (2000), « La taille de L'État et richesse des nations ", Institut Économique de Montréal, Montréal.

Johnson, Simon y Daniel Kaufmann y Pablo Zoido-Lobatón (1998), "Regulatory Discretion and the Unofficial Economy". American Economic Review.

Johnston, M. (1986), "The Political Consequences of Corruption". Comparative Politics, 459-477.

Johnston, M. (2000), Corruption and Democratic Consolidation. Department of Political Science, Colgate University.

Kaufmann, Daniel (1997), "Corruption: The Facts". World Bank Policy Working Paper.

Kaufmann, Daniel y Hellman, Joel S. (2001), "Confronting the Challenge of the State Capture in Transition Economies". Finance and Development, Vol. 38, $N^{\circ} 3$.

Keefer, Philip y Stephen Knack (1995), "Institutions and Economic Performance: Cross-Country Tests Using Alternative Institutional Measures". Economics and Politics, VII.

La Porta, Rafael, Lopez De Silanes, Florencio, Shleifer, Andrei y Vishny, Robert (1997), "Trust in Large Organizations". The American Economic Review, Papers and Proceedings, CXXXVII, Vol. 2, 333-8.

La Porta, Rafael, Lopez De Silanes, Florencio, Shleifer, Andrei y Vishny, Robert (1999), "The Quality of Government".
The Journal of Law, Economics and Organization, XV Vol. 1, 222-79.

La Porta, Rafael y Álvarez, S. (1997), La Corrupción Política. España. Alianza.

Lambsdorff, Johann (1999a), Corruption in International Research - A Review. Göettingen University Working Paper.

Lambsdorff, Johann (1999b), Exporter's Propensity to Pay Bribes. Göettingen University Working Paper.

Lederman, Daniel (2001), Accountability and Corruption: Political Institutions Matter. University of Chicago.

Leff, N. (1964), "Economic Development through Bureaucratic Corruption". American Behavioral Scientist, N 8/3.

Leite, Carlos y Jens Weidman (1999), Does Mother Nature Corrupt? Natural Resources, Corruption and Economic Growth. International Monetary Found Working Paper, 99/85.

Leys, C. (1970), "What is the Problem About Corruption?" en Heindenheimer, A.J. (Ed.) Political Corruption: Readings in Comparative Perspective. New York: Holt, Rinehart and Winston.

Lien, Donald (1986), "A Note on Competitive Bribery Games". Economic Letters, Vol. 22, 337-341.

Little, W. (1992), "Political Corruption in Latin America". Corruption and Reform, Vol. 7, 41 - 66, Kluwer Academic Publishers.

Lui, Francis (1985), "An Equilibrium Queuing Model of Bribery", Journal of Political Economy, 760-81.

Malem Seña, Jorge (2000), Globalización, Comercio Internacional y Corrupción. Barcelona, Editorial Gedisa.

Malem Seña, Jorge (2002), La Corrupción: Aspectos éticos, económicos, políticos y jurídicos, Barcelona, Editorial Gedisa.

Matza, D. y Sykes, G. (1957), "Techniques of Neutralization: A Theory of Delin- 
quency". American Sociological Review 22.

Mauro, Paolo (1995), "Corruption and Growth". Quarterly Journal of Economics. CX, 681-712.

Mauro, Paolo (1997), The Effects of Corruption on Growth, Investment and Government Expenditure. International Monetary Found Working Paper, 96/98.

Mauro, Paolo (1998), "Corruption: Causes, Consequences and Agenda for Further Research". Finance and Development, Vol. 35, № 1.

Morgan, Gareth (1999), Imágenes de la Organización. Madrid, Editorial Alfaomega Grupo Editor.

Naim, Moses (1995), "The Corruption Eruption". Brown Journal of World Affairs.

Narodov, Mira (1960), Atlas. Departamento de Geodesia y Cartografía del Comité Estatal Geológico de la URSS, Moscú.

Offe, Claus (1990), Contradicciones del Estado del Bienestar. Editorial Alianza, colección los noventa, México D.F.

Ortiz, Tulio (1997), "Aportes a una Historia de la Corrupción en la Argentina" en Sandler, H. y Rajland, B. (Eds.) Corrupción, una Sociedad Bajo Sospecha. Buenos Aires, La Ley.

Paldam, Martin (1999a), The Bid Pattern of Corruption. Economics, Culture and the Seesaw Dynamics. Aarhus University, Denmark.

Paldam, Martin (1999b), Corruption and Religion. Adding to the Economic Model. Aarhus University, Denmark.

Poirson, H. (1998), Economic Security, Private Investment and Growth in Developing Countries. International Monetary Found Working Paper, 98/4.

Pranab, Bardhan (1997), "Corruption and Development: A Review of Issues". Journal of Economic Literature, Vol. 35, Issue 3.
Pritzl, Rutger (2000), Corrupción y Rentismo en América Latina, Buenos Aires, Edición Ciedla-Fundación Konrad Adenauer.

Proud'Homme, R. (1995), "The Dangers of Decentralization". The World Bank Research Observer, Vol. 10, $\mathrm{N}^{\circ} 2$.

Przeworski, Adam (1998), "Acerca del diseño del Estado: Una perspectiva principal-agente". Revista Argentina de Ciencia Política, Diciembre.

Reos, Orlando (2002), "Efectos Económicos de la Corrupción". Documento de la División de Programas de Estado y Sociedad Civil 1. Banco Interamericano de Desarrollo.

Rose-Ackerman, Susan (1996), "The Political Consequences of Corruption. Causes and Consequences". World Bank, Note 74.

Rose-Ackerman, Susan (2001), La Corrupción y los Gobiernos. Barcelona, Editorial Siglo XX.

Sachs, Jeffrey D. (1995), "Natural Resource Abundance and Economic Growth". Discussion Paper № 517a, Cambridge.

Seligson, M. (2002), "The Impact of Corruption on Regime Legitimacy: A Comparative Study of Four Latin American Countries". The Journal of Politics, Vol. 64, Pp. $408-433$.

Shleifer, Anrei y Vishny, Robert (1993), "Corruption". Quarterly Journal of Economics, Vol. 103, № 3.

Suárez, Francisco y Christiensen, Adriana (2001), Aspectos Teóricos, Contextuales y Metodológicos en el Análisis Comparado de la Corrupción Organizacional. Trabajo del VI Congreso Internacional del CLAD, Buenos Aires.

Suárez, Francisco y Gorrochategui, Nora (1998), Corrupción Organizacional: Aspectos vinculados a la Estructura de Oportunidades en Diversos 
Tipos de Organizaciones y Casos de Corrupción Institucionalizados. Instituto de Investigaciones Administrativas de la Facultad de Ciencias Económicas de la Universidad de Buenos Aires.

Suárez, Francisco, Jabbaz, Marcela e Isuani, Fernando (2003), La Corrupción organizacional: Aportes Para el Desarrollo Teórico-Conceptual. Instituto de Investigaciones Administrativas de la Facultad de Ciencias Económicas de la Universidad de Buenos Aires. Buenos Aires.

Sutherland, E. y Cressey, D. (1966), Principles of Criminology. Philadelphia. Lippincott.

Swamy, Anand (1999), Gender and Corruption. Draft Paper, Iris Center, University of Maryland.

Sztompka, Piotr (1997), "Trust, distrust and the paradox of democracy". Centro Científico de Berlín para la Investigación Social. Disponible en http://skylla.wzberlin.de/pdf/1997/p97-003.pdf

Tanzi, Vittorio (2000), Policies, Institutions and the Dark Side of Economics. Chetenham. Edward Elgar.

Tanzi, Vittorio y Davoodi, H. (1998), Corruption, Public Investment and Growth. International Monetary Found Working Paper, 97/139.

Tapscott, C. (2001), Confidence and Trust The Institutional Prerequisites for Local Governance in South Africa. Universitas Bergensis Working Paper.

Theobald, R. (1990), Corruption, Development and Underdevelopment. Durham. Duke University Press.

Tiihonen, Paula (2003), "Good Governance and Corruption in Finland" International Institute of Administrative Sciences, Bruxelles.

Tocqueville, Alexis [1840 (2001)], De la Démocratie en Amérique. Richard D.
Heffner (Ed.) Mass Market Paperback.

Transparency International (2002), Corruption Perceptions Index. Berlin, August.

Treisman, Deobald (2000), The Causes of Corruption: A Cross National Study. University of California.

Trujillo Arjona, A. (2002), La Corrupción Política: Una Revisión de la Literatura. Universidad Carlos III de Madrid, Documento de Trabajo 02-14.

Van Rijckeghem, Caroline y Weder, Beatrice (1997), Corruption and the Rate of Temptation: Do Low Wages in the Civil Service Cause Corruption? International Monetary Found Working Paper, 97/73.

Varese, Federico (2001), "Pervasive Corruption", Working Paper, disponible en www.colbud.hu/honesty-trust/varese/pub01.htm

Weber, Max [1905 (1991)], La Ética Protestante y el Espíritu del Capitalismo. México. La Red de Jonás.

Wei, Shang-Jin (1997a), How Taxing is Corruption on International Investors. National Bureau of Economic Research Working Paper 6030, Cambridge.

Wei, Shang-Jin (1997b), Why is Corruption so Much More Taxing Than Tax. National Bureau of Economic Research Working Paper 6030, Cambridge.

Wei, Shang-Jin (2000), "Local Corruption and Global Capital Flows". Working Papers on Economic Activity, Vol. 2.

Weingast, Barry R. (1995), "The Economic Role of Political Institutions: market Preserving Federalism and Economic Development", Journal of Law, Economics and Organization, Vol. 11, $\mathrm{N}^{\circ} 1$.

Weyland, Kurt (1998), "The Politics of Corruption in Latin America”. Journal of Democracy $9,108-21$. 
Tipos de Organizaciones y Casos de Corrupción Institucionalizados. Instituto de Investigaciones Administrativas de la Facultad de Ciencias Económicas de la Universidad de Buenos Aires.

Suárez, Francisco, Jabbaz, Marcela e Isuani, Fernando (2003), La Corrupción organizacional: Aportes Para el Desarrollo Teórico-Conceptual. Instituto de Investigaciones Administrativas de la Facultad de Ciencias Económicas de la Universidad de Buenos Aires. Buenos Aires.

Sutherland, E. y Cressey, D. (1966), Principles of Criminology. Philadelphia. Lippincott.

Swamy, Anand (1999), Gender and Corruption. Draft Paper, Iris Center, University of Maryland.

Sztompka, Piotr (1997), "Trust, distrust and the paradox of democracy". Centro Científico de Berlín para la Investigación Social. Disponible en http://skylla.wzberlin.de/pdf/1997/p97-003.pdf

Tanzi, Vittorio (2000), Policies, Institutions and the Dark Side of Economics. Chetenham. Edward Elgar.

Tanzi, Vittorio y Davoodi, H. (1998), Corruption, Public Investment and Growth. International Monetary Found Working Paper, 97/139.

Tapscott, C. (2001), Confidence and Trust The Institutional Prerequisites for Local Governance in South Africa. Universitas Bergensis Working Paper.

Theobald, R. (1990), Corruption, Development and Underdevelopment. Durham. Duke University Press.

Tiihonen, Paula (2003), "Good Governance and Corruption in Finland" International Institute of Administrative Sciences, Bruxelles.

Tocqueville, Alexis [1840 (2001)], De la Démocratie en Amérique. Richard D.
Heffner (Ed.) Mass Market Paperback.

Transparency International (2002), Corruption Perceptions Index. Berlin, August.

Treisman, Deobald (2000), The Causes of Corruption: A Cross National Study. University of California.

Trujillo Arjona, A. (2002), La Corrupción Política: Una Revisión de la Literatura. Universidad Carlos III de Madrid, Documento de Trabajo 02-14.

Van Rijckeghem, Caroline y Weder, Beatrice (1997), Corruption and the Rate of Temptation: Do Low Wages in the Civil Service Cause Corruption? International Monetary Found Working Paper, 97/73.

Varese, Federico (2001), "Pervasive Corruption", Working Paper, disponible en www.colbud.hu/honesty-trust/varese/pub01.htm

Weber, Max [1905 (1991)], La Ética Protestante y el Espíritu del Capitalismo. México. La Red de Jonás.

Wei, Shang-Jin (1997a), How Taxing is Corruption on International Investors. National Bureau of Economic Research Working Paper 6030, Cambridge.

Wei, Shang-Jin (1997b), Why is Corruption so Much More Taxing Than Tax. National Bureau of Economic Research Working Paper 6030, Cambridge.

Wei, Shang-Jin (2000), "Local Corruption and Global Capital Flows". Working Papers on Economic Activity, Vol. 2.

Weingast, Barry R. (1995), "The Economic Role of Political Institutions: market Preserving Federalism and Economic Development", Journal of Law, Economics and Organization, Vol. 11, $\mathrm{N}^{\circ} 1$.

Weyland, Kurt (1998), "The Politics of Corruption in Latin America”. Journal of Democracy $9,108-21$. 